Subscriber access provided by Lib4RI - Library for Eawag, Empa, PSI \& WSL

\title{
Article
}

\section{Drying and pyrolysis of cellulose nanofibers from wood, bacteria and algae for char application in oil absorption and dyes adsorption}

Jana Štefelová, Vaclav Slovak, Gilberto Siqueira, Richard T. Olsson, Philippe Tingaut, Tanja Zimmermann, and Houssine Sehaqui

ACS Sustainable Chem. Eng., Just Accepted Manuscript •DOI: 10.1021/ acssuschemeng.6b03027 • Publication Date (Web): 31 Jan 2017

Downloaded from http://pubs.acs.org on February 2, 2017

\section{Just Accepted}

\begin{abstract}
"Just Accepted" manuscripts have been peer-reviewed and accepted for publication. They are posted online prior to technical editing, formatting for publication and author proofing. The American Chemical Society provides "Just Accepted" as a free service to the research community to expedite the dissemination of scientific material as soon as possible after acceptance. "Just Accepted" manuscripts appear in full in PDF format accompanied by an HTML abstract. "Just Accepted" manuscripts have been fully peer reviewed, but should not be considered the official version of record. They are accessible to all readers and citable by the Digital Object Identifier (DOI $®$ ). "Just Accepted" is an optional service offered to authors. Therefore, the "Just Accepted" Web site may not include all articles that will be published in the journal. After a manuscript is technically edited and formatted, it will be removed from the "Just Accepted" Web site and published as an ASAP article. Note that technical editing may introduce minor changes to the manuscript text and/or graphics which could affect content, and all legal disclaimers and ethical guidelines that apply to the journal pertain. ACS cannot be held responsible for errors or consequences arising from the use of information contained in these "Just Accepted" manuscripts.
\end{abstract}




\title{
Drying and pyrolysis of cellulose nanofibers from
}

\section{wood, bacteria and algae for char application in oil absorption and dyes adsorption}

\author{
Jana Štefelovát ${ }^{\dagger,}$, Václav Slovák $k^{\dagger}$, Gilberto Siqueira ${ }^{\ddagger}$, Richard T. Olsson ${ }^{\S}$, Philippe Tingaut ${ }^{\ddagger}$, Tanja \\ Zimmermann $^{\ddagger}$ and Houssine Sehaqui, ${ }^{\ddagger}$ \\ ${ }^{\dagger}$ Department of Chemistry, Institute of Environmental Technologies, Faculty of Science, University of \\ Ostrava, 30. dubna 22, 70103 Ostrava, Czech Republic \\ ${ }^{\ddagger}$ Empa, Swiss Federal Laboratories for Materials Science and Technology, Applied Wood Materials \\ Laboratory, Überlandstrasse 129, CH-8600, Dübendorf, Switzerland \\ ${ }^{\S}$ KTH, Royal Institute of Technology, Fiber and Polymer Technology, School of Chemical Science \\ and Engineering, Teknikringen 56, SE-100 44 Stockholm, Sweden \\ * To whom correspondence should be addressed. Tel.: +41 5876561 18. Fax: +41 5876540 07. E- \\ mail: Houssine.sehaqui@empa.ch (H. Sehaqui).
}




\section{Abstract}

Native cellulose nanofibers (CNF) constitute an abundant resource for pyrolysis leading to char materials offering a wide range of properties and application possibilities. With the aim to produce chars having large surface area and pore volume for dyes adsorption and oil absorption, respectively, we herein explore the slow pyrolysis process of cellulose nanofibers from wood, Cladophora algae and bacteria that were subjected to various drying routes. Whereas algae CNF with their large crystallites lead to high surface area $\left(\mathrm{S}_{\mathrm{BET}}\right)$ substrates using conventional drying from aqueous suspension, CNF from wood having smaller crystallites require drying from solvents to reach high $\mathrm{S}_{\mathrm{BET}}$ substrates, which results in chars with a good adsorption capacity for both anionic and cationic dyes. Moreover, the porosity of the CNF substrate can be tuned via an ice-templating freeze-drying procedure reaching values as high as $99.7 \%$ and corresponding chars capable of absorbing $64-120$ g.g-

${ }^{1}$ of various oils and organic solvents. Besides the absorption/adsorption properties of the chars, we report effects of CNF source and structure on the thermal properties assessed by thermogravimetric and thermomechanical analyses, differential scanning calorimetry and mass spectrometry, and we identified over 20 decomposition products and 3 expansion events occurring during CNF pyrolysis.

KEYWORDS: Cellulose nanomaterials, Thermal decomposition, Activation energy, TG-MS, Thermomechanical analysis, Environmental remediation. 


\section{$1 \quad$ Introduction}

Industrialization and human activities have led to an increasing number of pollutants entering our environment, thus urging for sustainable remediation solutions. ${ }^{1,2}$ Such solution requires the combination of sustainable materials and processing technologies offering enhanced performance compared to current remediation methods. Thus, the role of cellulose nanofibers $(\mathrm{CNF})$ in these depollution technologies is expected to grow due to their abundance, environmentally benign character and large surface area where functional entities could be included for specific interaction with contaminants. ${ }^{3}$ Functional cellulose nanofibers have been used in aqueous systems for the adsorption of heavy metal ions, ${ }^{4,5}$ dyes, ${ }^{6,7}$ radioactive species, ${ }^{8}$ organic matter, ${ }^{9}$ bacteria and viruses, ${ }^{7}$ nitrate and fluoride, ${ }^{10,11}$ and in the atmosphere for carbon dioxide capture. ${ }^{12,}{ }^{13}$ To absorb/adsorb non-polar species, hydrophobization of $\mathrm{CNF}$, which can be e.g. achieved through attachment of hydrocarbon chains, ${ }^{14-16}$ application of an inorganic coating, ${ }^{17-19}$ or pyrolysis is necessary. The development of an economical hydrophobic CNF-based sorbent would contribute to environmental depollution for the removal of organic compounds from air and water. For instance, it can be used for cleanup of oil spills from aquatic medium and for the treatment of oily and dye-contaminated industrial wastewater. $17,20-22$

While activated carbon is being largely used for water and air purification, its preparation requires large quantities of activating agents like $\mathrm{ZnCl}_{2}, \mathrm{H}_{3} \mathrm{PO}_{4}, \mathrm{KOH}$ (chemical activation), or a high temperature combined with steam, carbon dioxide or air atmospheres (physical activation). ${ }^{23} \mathrm{CNF}$ is therefore an interesting substrate for pyrolysis since the material structure from various CNF sources and from various drying pathways of CNF suspensions offer a wide array of substrates whose pyrolysis should lead, without an activation step, to numerous material structures of potential interests as high surface area adsorbents, ${ }^{22,}{ }^{24}$ catalysts, ${ }^{26}$ energy storage devices ${ }^{23,}{ }^{25}$ and sensors. ${ }^{26,27,} 28$ Furthermore, a better understanding of the cellulose pyrolysis mechanisms necessitates the exploration of various material structures, and could ultimately lead to a more efficient biofuel production. 
CNF are obtained either through a top-down approach from woody, plant, or algal biomass wherein the major part of non-cellulosic components is first removed, which is followed by a mechanical disintegration of the obtained pulp in the presence of water, ${ }^{29-31}$ or through a bottom-up approach by cultivating Acetobacter xylinum in the presence of sugar (also known as bacterial cellulose). ${ }^{32}$ While displaying the cellulose I crystalline structure of native cellulose, these CNF have different crystal size, degree of polymerization and proportions of $I_{\alpha}$ and $I_{\beta}$ allomorphs. ${ }^{33}$ In addition, various drying routes of the aqueous CNF suspension result in different material structures, which in turn affect the final material's properties. ${ }^{34-40}$ Hence, it becomes apparent that the pyrolysis process of native cellulose and the resulting char material can be adequately represented only when the structure of the CNF substrate is comprehended, taking into account its hierarchical structure, and this is the purpose of the present work.

Here, we adopt a bottom-up approach to investigate the pyrolysis process of cellulose and the adsorption/absorption properties of the chars. We first examine physical properties of raw CNF from various sources (wood, bacteria and Cladophora algae), we then analyze the structure and thermal properties of CNF obtained via different drying routes of CNF gels, and we finally evaluate the structure and adsorption/absorption properties of CNF chars. Various analytical tools including thermogravimetric and thermomechanical analyses, differential scanning calorimetry, mass spectrometry and elemental analysis were employed in order to generate complementing data whose interpretation allowed for a thermal degradation pathway of CNF discerning phenomena occurring in the crystalline and amorphous portions of cellulose to be proposed.

\section{Experimental Methods}

CNF extraction. Cellulose nanofibers from bleached softwood pulp fibers (ECF, Stendal Berlin, Germany) denoted WCNF were prepared by mechanical disintegration of the pulp at $2 \mathrm{wt} \%$ combining a high shear grinding process at a nominal velocity of $1500 \mathrm{rpm}$ of the rotating grinding stones (Supermass Colloider MKZA10-20J CE, Masuko Sangyo Co., Japan), and a homogenization whereby the suspension underwent two passes through $400 \mu \mathrm{m}$ and $200 \mu \mathrm{m}$ chambers, then another 
two passes through $200 \mu \mathrm{m}$ and $75 \mu \mathrm{m}$ chambers under a pressure of up to 1200 bars (Microfluidizer ${ }^{\circledR}$ High-Shear Processor, Microfluidics Corporation, USA). ${ }^{41}$ Bacterial cellulose nanofibers (BCNF) were prepared as described elsewhere. ${ }^{42}$ BCNF hydrogels with $\sim 1$ vol $\%$ cellulose fraction were produced by the bacterial strain Acetobacter xylinum FF-88 using a culture of 5 vol\% of coconut milk and 8 vol\% of sucrose. The hydrogel was boiled in $10 \mathrm{vol} \%$ of a concentrated $\mathrm{NaOH}$ solution for $3 \mathrm{~h}$, then thoroughly washed with distilled water and Milli-Q water. BCNF hydrogel thus obtained was homogenized by an Ultraturax T25 homogenizer for 5 min to produce BCNF suspension. Cladophora algae were collected from the Chriesbach creek in the region of Zurich, and used for the preparation of algae cellulose nanofibers (ACNF) following the procedure described by Mihranyan et al. ${ }^{43}$ Cladophora glomerata algae at $2 \mathrm{wt} \%$ in water were treated 3 times with a $1 \mathrm{wt} \% \mathrm{NaOH}$ solution at $80^{\circ} \mathrm{C}$ for $2 \mathrm{~h}$ under mechanical stirring. The fibers were thereafter filtered and washed with distilled water and subsequently bleached at $80{ }^{\circ} \mathrm{C}$ for $4 \mathrm{~h}$ under mechanical stirring. The bleaching solution comprises of equal parts acetate buffer, aqueous chlorite (1.7 wt \% in water), and distilled water. The fibers were then filtered, washed with distilled water and treated with $2.5 \mathrm{~N} \mathrm{HCl}$ for 70 min under reflux and mechanical stirring. The suspension was finally washed until neutrality, dialyzed against distillated water, and homogenized by an Ultraturax T25 homogenizer for 5 min to produce ACNF suspension.

CNF drying. Heat drying (HD): A paper-making approach was used for the preparation of the heatdried substrate. $^{35,43} 400 \mathrm{mg}$ (dry weight) of CNF in water at a total volume of $300 \mathrm{ml}$ was vacuum filtered on a glass filter funnel $(8 \mathrm{~cm}$ in diameter) using a $0.65 \mu \mathrm{m}$ DVPP filter membrane from Millipore, and the resulting cake was hot pressed at $120^{\circ} \mathrm{C}$ for 20 minutes under a pressure of 2.2 bars (Carver Inc., USA) giving a film denoted as the HD substrate. Supercritical $\mathrm{CO}_{2}$ drying (SCD): The resulting cake from CNF suspension filtration (400 mg dry weight) was solvent exchanged to ethanol, then to liquid $\mathrm{CO}_{2}$ in a critical point dryer chamber (E3000, Quorum technologies). The chamber was then brought above the $\mathrm{CO}_{2}$ critical point conditions to ca. 100 bar and $36^{\circ} \mathrm{C}$, and depressurized leading to an aerogel denoted as the SCD substrate. ${ }^{38}$ Freeze-drying (FD): An aqueous CNF suspension at $0.5 \mathrm{wt} \%$ was placed in a copper mold $\left(15 * 15 \mathrm{~cm}^{2}\right)$ and frozen in liquid nitrogen, then 
sublimated under vacuum with a Lyovac freeze-dryer (SRK system technik GMBH) yielding a foam having a density of $\sim 5 \mathrm{~kg} \mathrm{~m}^{-3}$ denoted as the FD substrate. FD substrates having other densities were prepared similarly by freeze-drying CNF suspensions having a concentration of $0.3 \%, 1.5 \%, 3.5 \%$ or 5.4\%, as reported elsewhere. ${ }^{35,40}$ Tert-butanol freeze-drying (BuFD): The aqueous CNF suspension was solvent-exchanged to t-butanol via successive t-butanol addition, centrifugation and removal of supernatant. The CNF in t-butanol was thereafter frozen in liquid nitrogen, then sublimated under vacuum with a Lyovac freeze-dryer (SRK system technik GMBH) yielding BuFD substrate. ${ }^{37,39}$

CNF substrates characterization. $C N F$ substrate density $\left(\rho_{\mathrm{CNF}}\right)$ was calculated by dividing the weight of the dry CNF substrate by its volume determined using a micrometer with a precision of $1 \mu \mathrm{m}$. The porosity of CNF substrate $(\mathrm{P})$ was given by: $\mathrm{P}=1-\rho_{\mathrm{CNF}} / \rho_{\text {cellulose }}$ by taking $1500 \mathrm{~kg} \mathrm{~m}^{-3}$ as the density of cellulose $\left(\rho_{\text {cellulose }}\right){ }^{44}$ The specific surface area of the CNF substrates $\left(\mathrm{S}_{\mathrm{BET}}\right)$ was determined according to the multipoint Brunauer-Emmett-Teller (BET) method by $\mathrm{N}_{2}$ physisorption at relative vapor pressure of $0.05^{-0.2}$ on a surface area and pore size analyser (Coulter SA3100, Beckman coulter Inc). Scanning Electron Microscopy was carried out using a FEI Nova NanoSEM 230 instrument (FEI, Hillsboro, Oregon, USA) at an accelerating voltage of $5 \mathrm{kV}$ and a working distance of $5 \mathrm{~mm}$. Prior to SEM observation, the samples were sputter-coated with a platinum layer of about 7.5 nm (BAL-TEC MED 020 Modular High Vacuum Coating Systems, BAL-TEC AG, Liechtenstein) in Ar as a carrier gas at $510^{-2}$ mbar. Dynamic vapour sorption experiments were performed in a VTISA+ Vapor Sorption Analyzer (TA-Instruments, New Castle, USA). A sample weighing ca. $10 \mathrm{mg}$ was placed in the sample cup and dried at $105^{\circ} \mathrm{C}$ for 2 hours. Thereafter, the weight of the sample compared to a reference empty cup was registered with a resolution of $0.1 \mu \mathrm{g}$ while the relative humidity surrounding the cups was controlled in the range 10\%-95\%. Samples were tested at a temperature of $23^{\circ} \mathrm{C}$. X-ray diffraction analyses of CNF substrates were registered in a PANanalytical X'Pert PRO $\theta-2 \theta$ MPD system $(\mathrm{Cu}-\mathrm{K} \alpha$ radiation $\lambda=1.54060 \AA)$. The diffraction patterns were obtained from $5^{\circ}$ to $40^{\circ}$ in $2 \theta$ with angular step interval of $0.017^{\circ}$. The Segal crystallinity indexes (CI) were calculated according to XRD peak height method (Segal method), i.e., $\mathrm{CI}(\%)=100 *\left(1-\mathrm{I}_{1} / \mathrm{I}_{2}\right)$, where $I_{1}$ is the minimum intensity of the amorphous phase $\left(\sim 19^{\circ}\right)$ and $I_{2}$ is the maximum intensity of 
the crystalline phase $\left(\sim 22.5^{\circ}\right){ }^{45}$ The d-spacing was determined from Bragg equation, and the crystallite size perpendicular to the plan (L) was calculated using the Scherrer equation: $\mathrm{L}=0.9 \lambda /(\mathrm{H} \cdot \cos \theta)$ where $\mathrm{H}$ is the full-width at half-maximum and $\theta$ is the Bragg angle. ${ }^{46}$ Elemental analyses of carbon, oxygen and hydrogen in the CNF were performed by the microelemental laboratory of ETH Zurich on a LECO CHN-900 instrument (Leco Corporation, St. Joseph, MI, USA).

CNF pyrolysis and thermal properties. CNF samples were pyrolysed in a furnace under a nitrogen flow of $\sim 110 \mathrm{ml} \mathrm{min}^{-1}$ at $500{ }^{\circ} \mathrm{C}$ for 1 hour using a heating rate of $10 \mathrm{~K} \mathrm{~min}^{-1}$ (Carbolite, Liwag Industrieofenbau und Wärmetechnik AG furnace). Thermogravimetric analysis was performed on Setsys Evolution device (Setaram) interconnected with a mass spectrometer QMG 700 (Pfeiffer) coupled by Supersonic system (Setaram) for analysis of evolved gases. All measurements were performed using $\alpha-\mathrm{Al}_{2} \mathrm{O}_{3}$ crucibles in argon atmosphere $\left(20 \mathrm{ml} \mathrm{min}{ }^{-1}\right)$. The temperature programme consisted of drying at $100{ }^{\circ} \mathrm{C}$ for 1 hour to remove adsorbed moisture, followed by a linear heating to $500{ }^{\circ} \mathrm{C}$ with the rate of $10 \mathrm{~K} \mathrm{~min}^{-1}$. The mass spectrometer worked in multi-ion detection mode and ions with signal of $\mathrm{m} / \mathrm{z}$ between 2 and 126 were analysed during heating to identify thermal degradation products of cellulose pyrolysis at $10 \mathrm{~K} \mathrm{~min}^{-1}$. From TGA graph, the temperature at the onset of weight loss $\left(\mathrm{T}_{\text {onset }}\right)$ is taken as the temperature at $1 \%$ weight loss. The kinetic evaluation of thermogravimetric data was based on one-step approximation (mathematical description of pyrolysis process as one reaction) and the use of isoconversional principle. ${ }^{89,90}$ The Ozawa ${ }^{60}$ and Starink ${ }^{61}$ equations were used for calculation of dependence of apparent activation energy $E_{a}$ on conversion. TMA analysis was performed on Setsys Evolution device (Setaram) with thermomechanical modulus. The measurements were carried out in argon atmosphere $\left(20 \mathrm{ml} \mathrm{min}^{-1}\right)$ with a load of $5 \mathrm{~g}$ using quartz hemispherical flat probe. The temperature programme consisted of a linear heating to $500{ }^{\circ} \mathrm{C}$ with the heating rate of $1 \mathrm{~K} \mathrm{~min}^{-1}$.

Organic solvent and oil absorption. The solvents selected for the test were acetone, ethanol, toluene, chloroform and dodecane. These have a purity of at least $99 \%$. Shell rimula R6 LME 5w-30 was used as motor oil. Mineral oil (Hydroseal G250H) and silicone oil were supplied by Falcone chemical 
Specialties Ltd (Siebnen, Switzerland). In the absorption experiment, a piece of the char weighing ca. $10 \mathrm{mg}$ was dipped in $20 \mathrm{ml}$ of the oil/solvent for 5 seconds, and weighed to determine its absorption capacity i.e., the weight of the absorbed liquid divided by the dry weight of the char material. 3 replicates per sample were performed and the results were averaged.

Dye adsorption. Methylene blue (MB), crystal violet (CV) or congo red (CR) were dissolved in water at various concentrations and put in contact with the char at $\sim 1 \mathrm{~g} \mathrm{~L}^{-1}$ and shaken at $150 \mathrm{~min}^{-1}$ (IKA HS 260). Aliquots of the solution were then taken at given time intervals to measure their dye concentration via UV spectrophotometry at the maximum absorption wavelength of the dyes $(664 \mathrm{~nm}$ for methylene blue, $497 \mathrm{~nm}$ for congo red and $590 \mathrm{~nm}$ for crystal violet).

A list of abbreviations used in the present work is given in table 1.

Table 1. Abbreviation list

\begin{tabular}{|l|l|}
\hline CNF & Cellulose nanofibers \\
\hline WCNF & Cellulose nanofibers from wood \\
\hline BCNF & Cellulose nanofibers from bacteria \\
\hline ACNF & Cellulose nanofibers from Cladophora algae \\
\hline HD & Heat-drying \\
\hline FD & Freeze-drying \\
\hline SCD & Supercritical CO $_{2}$ drying \\
\hline BuFD & Tert-butanol freeze-drying \\
\hline $\mathrm{S}_{\mathrm{BET}}$ & Specific surface area according to BET method \\
\hline BJH & Barrett-Joyner-Halenda (sorption analysis) \\
\hline$\rho_{\mathrm{CNF}}$ & Density of the CNF substrate \\
\hline$\rho_{\text {cellulose }}$ & Density of cellulose \\
\hline $\mathrm{P}$ & Porosity \\
\hline XRD & X-ray diffraction \\
\hline CI & Crystallinity index \\
\hline L & Crystallite size \\
\hline TGA & Thermogravimetric analysis \\
\hline TMA & Thermomechanical analysis \\
\hline MS & Mass spectrometry \\
\hline $\mathrm{T}_{\text {onset }}$ & $\begin{array}{l}\text { Temperature at the onset (1\%) of thermal } \\
\text { degradation }\end{array}$ \\
\hline DSC & Differential scanning calorimetry \\
\hline SEM & Scanning electron microscopy \\
\hline TEM & Transmission electron microscopy \\
\hline MB & Methylene blue \\
\hline CV & Crystal violet \\
\hline CR & Congo red \\
\hline
\end{tabular}

\section{Results and Discussion}


CNF originating from wood, bacteria or algae cellulose were prepared as an aqueous gel, and are denoted WCNF, BCNF, and ACNF, respectively. These CNF have the very similar elemental composition characteristic for cellulose (44\% carbon, $49 \%$ oxygen and $6 \%$ hydrogen; Supporting information S1) and x-ray diffraction peaks of native cellulose at $2 \theta$ angles of $14.8^{\circ}, 16.6^{\circ}, 22.3^{\circ}$ and $34.4^{\circ}$, corresponding to $1-10,110,200$ and 004 lattices (Figure 1). ${ }^{33,47}$ Their SEM micrographs show typical high aspect-ratio fibrils forming a network structure (Figure 1), while their TEM micrographs allow a more precise estimation of their diameter, which was 10-110 nm for WCNF and BCNF, and 5$20 \mathrm{~nm}$ for ACNF (Figure 1). TEM micrographs also reveal differences between CNF, namely ACNF are completely straight and uniform single fibrils, while BCNF and to a larger extent WCNF have a greater tendency to bend and bundle. We estimate that 2-4 fibrils associate to form BCNF, while at least 5 fibrils form WCNF. These latter have a great mobility and can easily bend forming a loop, and this is due to their low crystallinity. The crystallinity index (CI) and the crystallite size of various CNF were estimated from their XRD spectra (Table 2). WCNF have the lowest CI of $72 \%$ which is consistent with the small wood microfibril diameter $(\sim 3 \mathrm{~nm})$ presenting a large surface consisting of less ordered cellulose chains. ${ }^{48}$ BCNF have a CI of $90 \%$ and larger crystallites of $\sim 6 \mathrm{~nm}$, while ACNF present both the highest CI of $96 \%$ and crystal size $(\sim 12 \mathrm{~nm})$ reflecting the large microfibrils of Cladophora. ${ }^{49}$ The increase in the $\mathrm{CI}$ is expectedly accompanied by an increase in the crystallite size since the crystallite surface area corresponding to amorphous cellulose is diminished. 

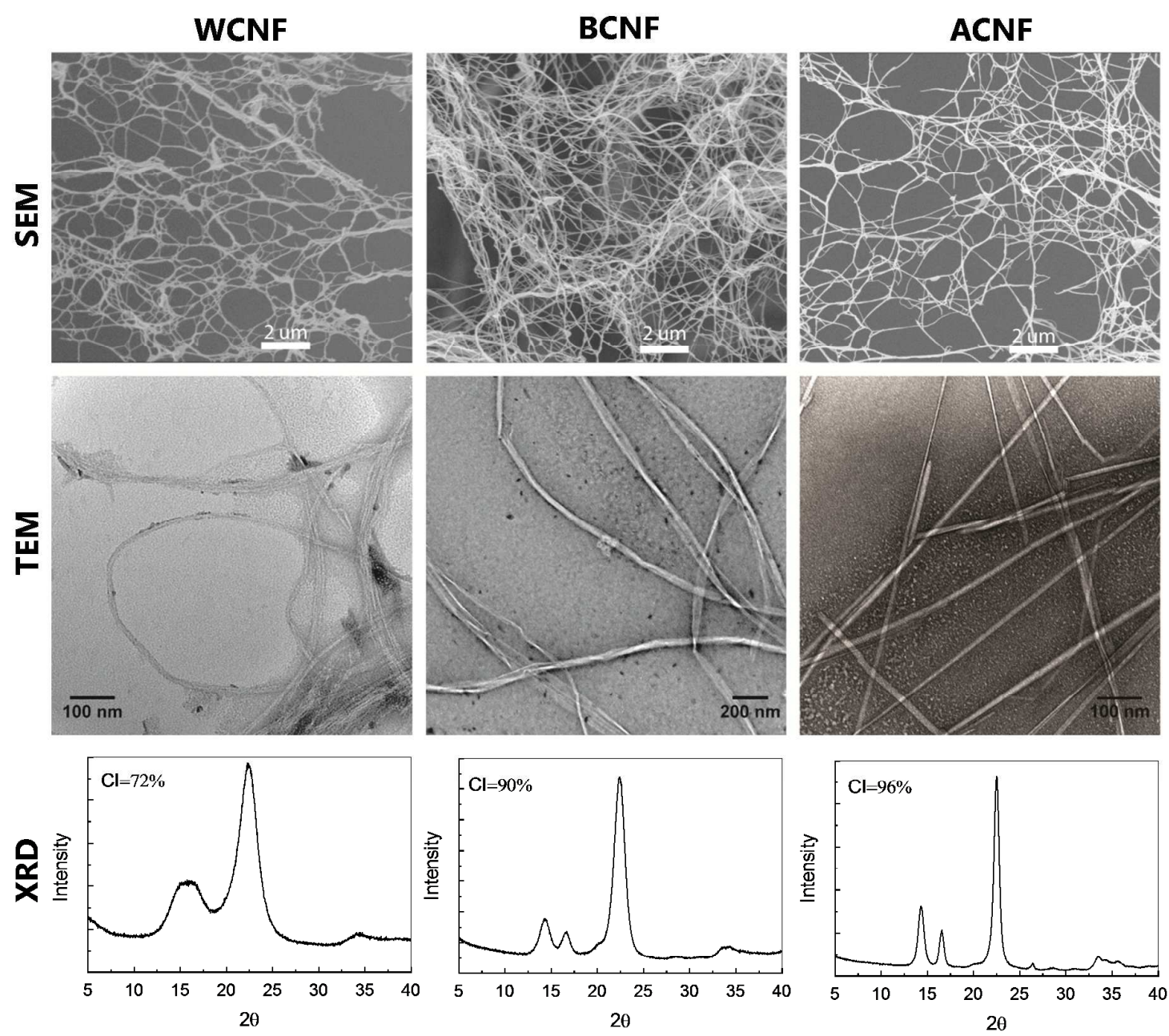

Figure 1. SEM / TEM micrographs and XRD spectra of WCNF, BCNF and ACNF. 
Table 2. CNF characteristics.

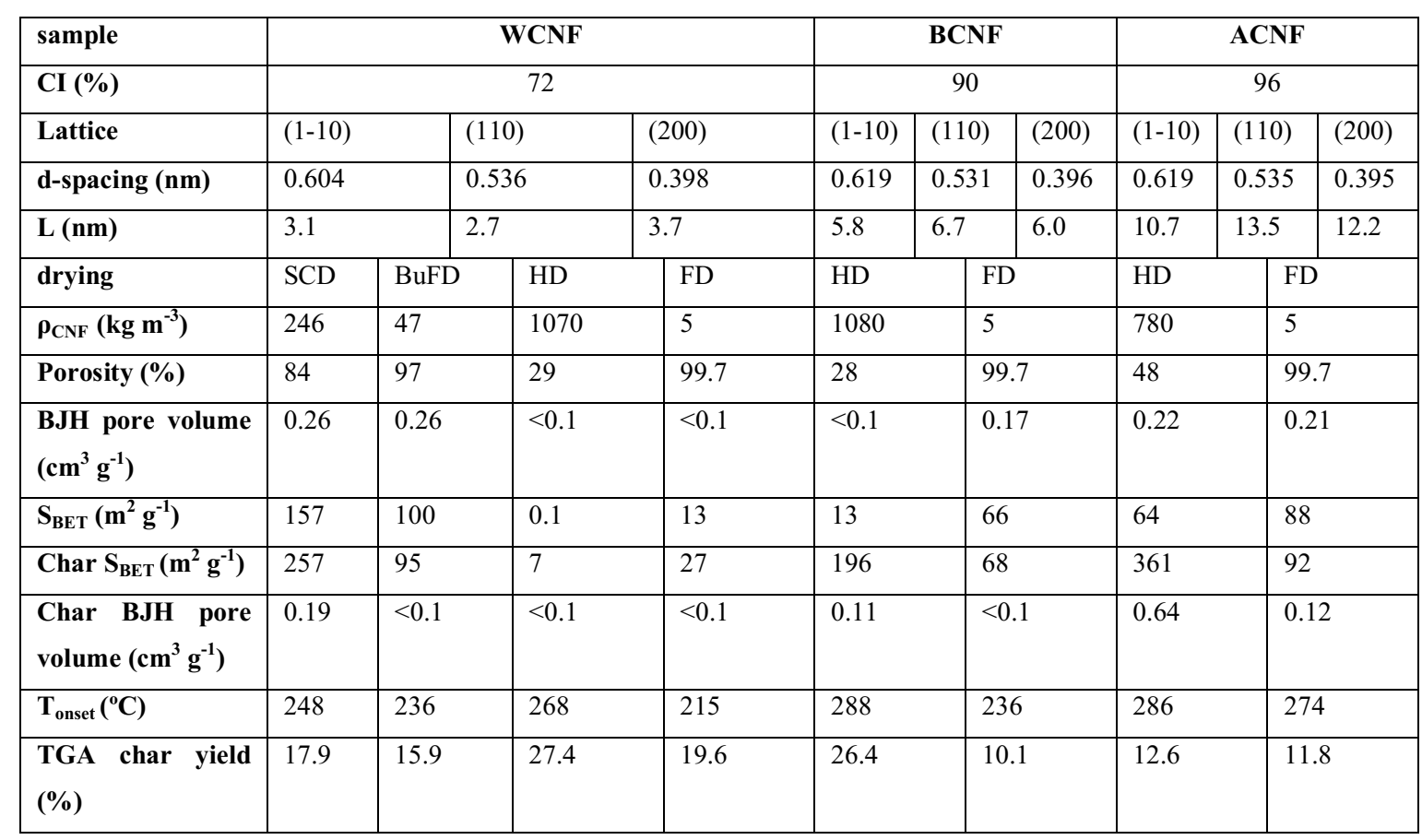

\section{Effect of WCNF drying on pyrolysis.}

Aqueous gels of WCNF were subjected to heat-drying (HD), freeze-drying (FD), tert-butanol freezedrying (BuFD) or supercritical $\mathrm{CO}_{2}$ drying (SCD). These drying routes are either from water-based (HD and FD) or solvent-based (BuFD and SCD) suspensions. The conventional HD of WCNF results in a massive aggregation of the fibrils forming a dense film $\left(\rho=1070 \mathrm{~kg} \mathrm{~m}^{-3}\right)$, (Figure 2). The aggregation of the fibrils occurs via their external surface formed by "amorphous" cellulose and is due to capillary forces acting on the fibrils during evaporation of water. ${ }^{34,36,50}$ Subsequently, the low specific surface area $\left(\mathrm{S}_{\mathrm{BET}}\right)$ of the HD sample $\left(0.1 \mathrm{~m}^{2} \mathrm{~g}^{-1}\right)$ determined by nitrogen adsorption indicates that the fibrils act collectively as a single mass, whose internal surface is not accessible to nitrogen molecules. FD results in a highly porous foam with a low density $\left(5 \mathrm{~kg} \mathrm{~m}^{-3}\right)$ and large pores reflecting the ice-crystals formed during the freezing step (Figure 2). ${ }^{35,40}$ The pores are surrounded by sheets constituted of aggregated fibrils (zoom in Figure 2), conferring the foam a moderate $\mathrm{S}_{\mathrm{BET}}$ of $13 \mathrm{~m}^{2} \mathrm{~g}^{-1}$. Drying WCNF from low polarity solvents is a mean to prevent their aggregation since surface tension effects are largely reduced. ${ }^{37,39,50,51}$ Consequently, BuFD results in highly porous foam with a finer structure compared to FD and a higher $\mathrm{S}_{\mathrm{BET}}$ of $100 \mathrm{~m}^{2} \mathrm{~g}^{-1}$ (Figure 2). Supercritical drying results in the 
substrate presenting the largest $\mathrm{S}_{\mathrm{BET}}\left(157 \mathrm{~m}^{2} \mathrm{~g}^{-1}\right)$ reflecting a preserved structure during drying attributed to the low polarity of $\mathrm{CO}_{2}$ and its gradual transition from the liquid to the gas phase via the supercritical fluid phase (Figure 2). ${ }^{38}$ Unlike the HD substrate, the fibrils in the SCD sample act as interconnected individual entities.

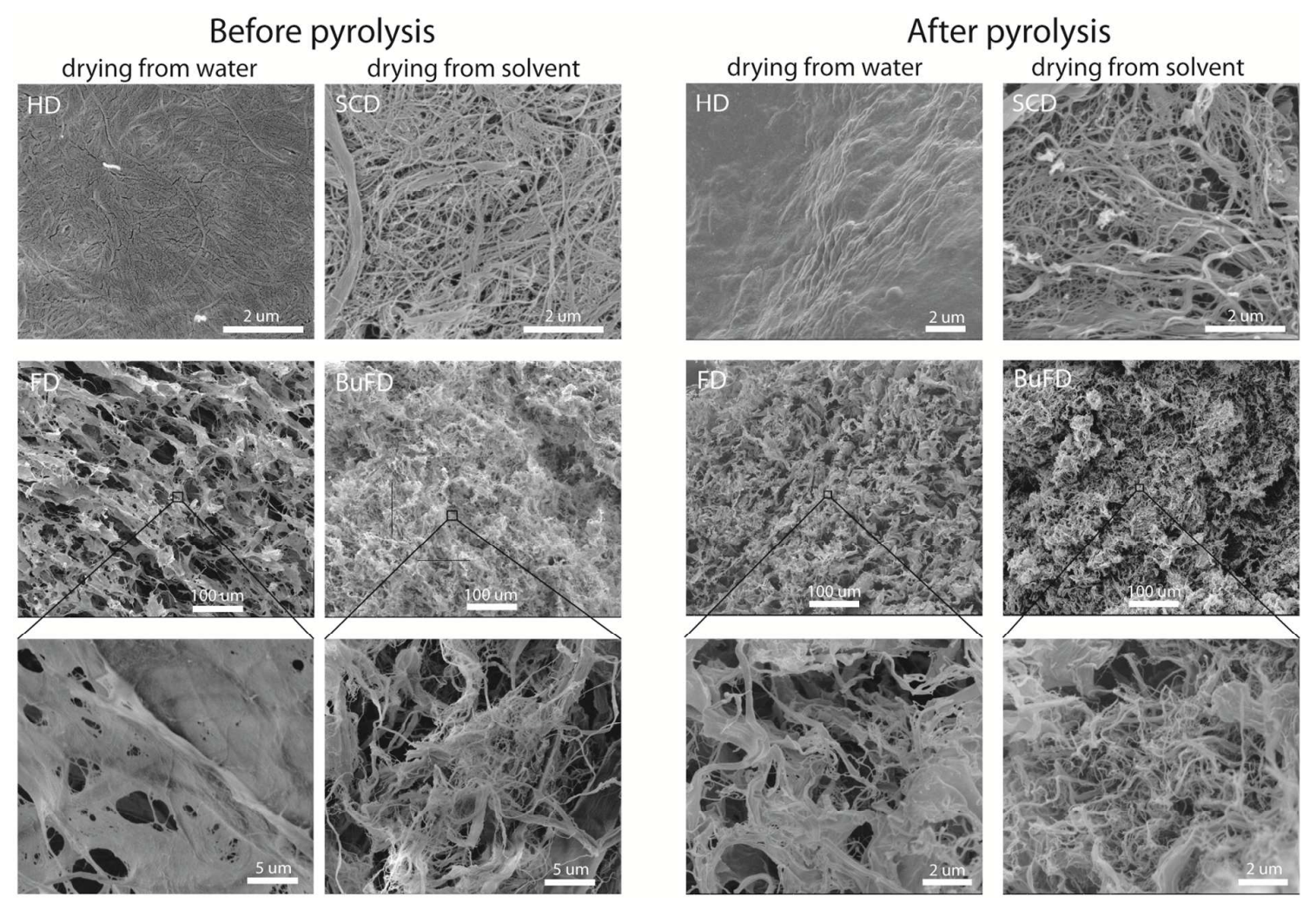

Figure 2. SEM micrographs of WCNF substrates and their corresponding chars. WCNF substrates are prepared via heat-drying (HD), Freeze-drying (FD), Supercritical $\mathrm{CO}_{2}$ drying (SCD), and Tert-butanol freeze-drying $(\mathrm{BuFD})$.

After pyrolysis of various WCNF substrates, most non-carbon elements are removed in a gaseous form via pyrolytic decomposition leading to char materials with a carbon content of $\sim 85 \%$ compared to the initial $44 \%$ carbon content of cellulose (Supporting information S2). SEM micrographs of these chars show a similar structure to their original form (Figure 2), in agreement with previous works. ${ }^{52,53}$ Pyrolysed HD sample displayed a dense structure without noticeable micro/nanostructure and a low $\mathrm{S}_{\mathrm{BET}}$, thus resembling the structure of the HD sample. Pyrolysed FD and BuFD samples maintained a high porosity after pyrolysis, with a higher surface area of the latter attributed to its finer structure prior to pyrolysis (Table 2). The pyrolysed SCD sample resulted in the highest $\mathrm{S}_{\mathrm{BET}}\left(257 \mathrm{~m}^{2} \mathrm{~g}^{-1}\right)$ 
reflecting the presence of the highest fraction of exposed nanofibers (also visible in Figure 2). The increase in the $\mathrm{S}_{\mathrm{BET}}$ of the pyrolysed SCD sample accompanying the pyrolysis process as compared to the quasi-constant $\mathrm{S}_{\mathrm{BET}}$ of the pyrolysed BuFD sample suggests a beneficial role of the sample's high density for the stabilisation of the carbonaceous sample nanostructure, and this is possibly due to higher density and mechanical properties of SCD sample preventing fibrils aggregation during pyrolysis. $^{37,38}$

Thermogravimetric analysis of various WCNF substrates is shown in Figure 3.a. Three distinct regions can be identified, i.e. evaporation of adsorbed moisture without thermal degradation at $\mathrm{T}<220^{\circ} \mathrm{C}$, major mass-loss stage at $220^{\circ} \mathrm{C}<\mathrm{T}<370{ }^{\circ} \mathrm{C}$, and minor mass-loss stage at $\mathrm{T}>370{ }^{\circ} \mathrm{C}$. The thermal behaviour of CNF is clearly affected by the drying, i.e., the structure of the sample. The temperature at the onset of weight loss $\left(\mathrm{T}_{\text {onset }}\right)$ correlates with the substrate's density (Figure 3.e), with a difference of $\sim 50{ }^{\circ} \mathrm{C}$ registered between $\mathrm{T}_{\text {onset }}$ of $\mathrm{HD}$ and $\mathrm{FD}$ substrates (Table 2). Difference in $\mathrm{T}_{\text {onset }}$ was also observed elsewhere in TGA thermograms of CNF prepared via various drying routes, ${ }^{54}$ which is in disagreement with results by Uetani et al. ${ }^{55}$ Since water is likely the first thermal decomposition product of cellulose pyrolysis, ${ }^{56}$ the difference in $\mathrm{T}_{\text {onset }}$ could be due to higher water vapour pressure encountered inside samples with higher density and this inhibits further dehydration.

Thereafter, there is a rapid weight loss during which over 20 products were identified by TG-MS during the thermal decomposition of WCNF including water, carbon monoxide and dioxide (Figure 3.c, Table 3, full MS spectra in Supporting information S3). At the end of the weight loss, WCNF substrates display different char yields (Table 2), and higher values are achieved for substrates dried from water (HD and FD) compared to substrates dried from solvent ( $\mathrm{SCD}$ and BuFD). This shows that the extent of fibrils aggregation influences the char yield. This latter is about twice as high for the HD sample presenting the least $\mathrm{S}_{\mathrm{BET}}$ compared to high surface area SCD and BuFD substrates. Hence, volatiles and tarry substances released during pyrolysis of low surface area substrates are trapped within the aggregated fibrils, leading to secondary reactions whereby char is formed. The higher weight loss rate of high surface area BuFD and SCD samples as compared to that of HD and FD 
samples (Figure 3.b) supports a short residence time of volatiles in the high $\mathrm{S}_{\mathrm{BET}}$ BuFD and SCD samples. These observations are in agreement with those by Peng et al. ${ }^{54}$

Pyrolysis of WCNF samples is accompanied by dimensional changes evaluated by thermomechanical analysis (Figure 3.d). Except the HD sample that expanded during heating, other substrates registered a noticeable shrinkage. The volume change correlates well with the char yield, i.e. samples presenting the lowest yield shrink the most (Figure 3.f). The large shrinkage observed for the BuFD sample indicates that this substrate is subjected to high stresses during pyrolysis, what can be explained by a combination of its high $\mathrm{S}_{\mathrm{BET}}$, low density and weak mechanical properties. ${ }^{37}$ The expansion of the HD sample is explained by its dense structure having low gas permeability, ${ }^{57,58}$ as indicated by its negligible $\mathrm{S}_{\mathrm{BET}}$. Hence, thermal degradation vapors released during heating of the HD substrate can hardly escape the sample and push its inner surfaces causing its expansion. The three expansion events occurring during heating of the WCNF at temperatures of $\sim 220^{\circ} \mathrm{C}, 240{ }^{\circ} \mathrm{C}$ and $270{ }^{\circ} \mathrm{C}$ indicate that there are mainly 3 thermal decomposition steps leading to vapor release during the slow pyrolysis process of WCNF.
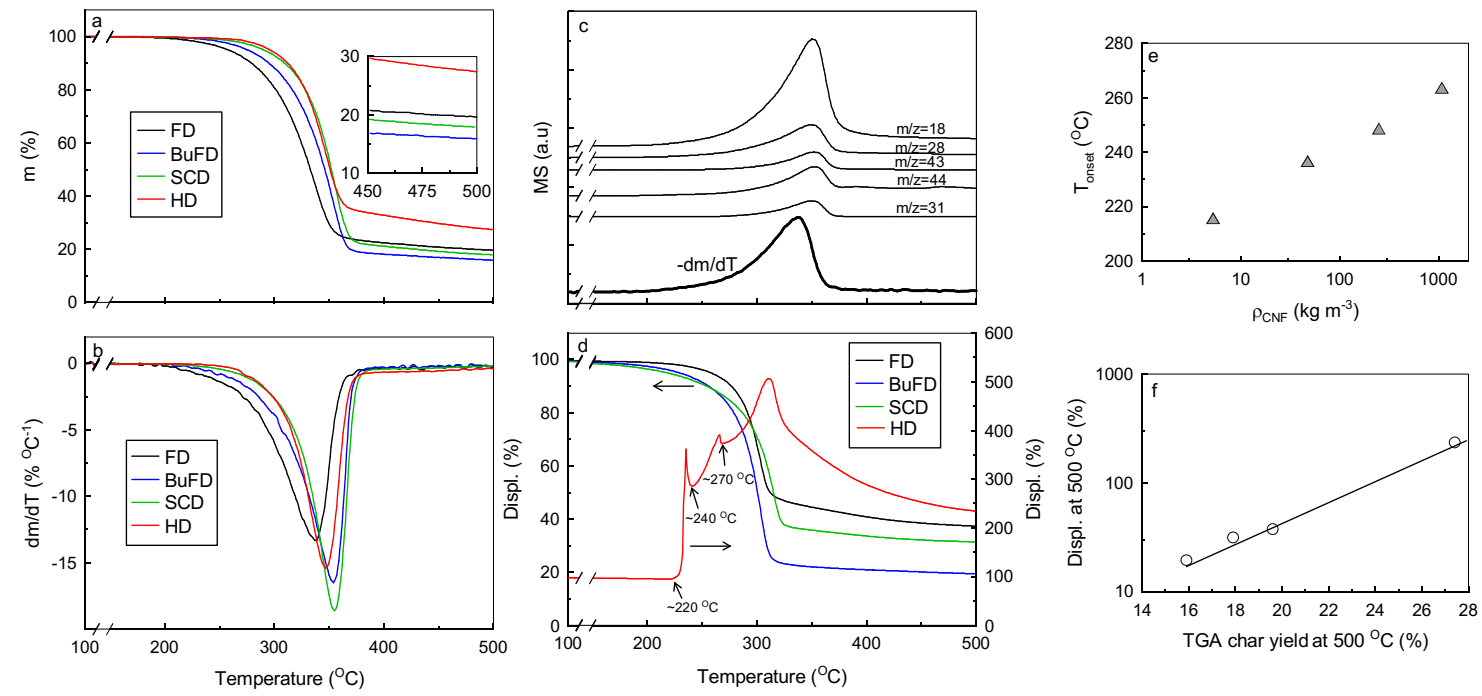

Figure 3. a. TGA, b. DTG, c. TG-MS and d. TMA analyses of WCNF. e. Relationship between $T_{\text {onset }}$ and CNF density. $\mathrm{f}$. Relationship between the TMA displacement and TGA char yield at $500{ }^{\circ} \mathrm{C}$.

Table 3. $\mathrm{m} / \mathrm{z}$ signals obtained by TG-MS and the possible corresponding compound/fragmented compound.

\begin{tabular}{|c|c|c|}
\hline $\mathbf{m} / \mathbf{z}$ & Possible compounds or fragmented compounds & Formula \\
\hline 2 & Hydrogen & $\mathrm{H}_{2}$ \\
\hline
\end{tabular}




\begin{tabular}{|c|c|c|}
\hline 12 & \multirow{4}{*}{ Hydrocarbons } & \multirow{4}{*}{$\mathrm{CH}_{\mathrm{x}}$} \\
\hline 13 & & \\
\hline 14 & & \\
\hline 15 & & \\
\hline 16 & Methane, derivates of hydrocarbons & $\mathrm{CH}_{4}, \mathrm{CH}_{\mathrm{x}} \mathrm{R}$ \\
\hline 17 & \multirow[t]{2}{*}{$x^{2}$} & \multirow{2}{*}{$\mathrm{H}_{2} \mathrm{O}$} \\
\hline 18 & & \\
\hline 28 & Carbon monoxide, formaldehyde & $\mathrm{CO}, \mathrm{CH}_{2} \mathrm{O}$ \\
\hline 29 & Acetaldehyde, hydroxyaldehyde, formaldehyde, formic acid & $\mathrm{C}_{2} \mathrm{H}_{4} \mathrm{O}, \mathrm{C}_{2} \mathrm{H}_{4} \mathrm{O}_{2}, \mathrm{CH}_{2} \mathrm{O}, \mathrm{HCOOH}$ \\
\hline 30 & Formaldehyde & $\mathrm{CH}_{2} \mathrm{O}$ \\
\hline 31 & Hydroxyaldehyde & $\mathrm{C}_{2} \mathrm{H}_{4} \mathrm{O}_{2}$ \\
\hline 32 & Hydroxyaldehyde, oxygen & $\mathrm{C}_{2} \mathrm{H}_{4} \mathrm{O}_{2}, \mathrm{O}_{2}$ \\
\hline 39 & Phenol, furan, furfural & $\mathrm{C}_{6} \mathrm{H}_{6} \mathrm{O}, \mathrm{C}_{4} \mathrm{H}_{4} \mathrm{O}, \mathrm{C}_{5} \mathrm{H}_{4} \mathrm{O}_{2}$ \\
\hline 41 & Hydroxymethylfurfural & $\mathrm{C}_{6} \mathrm{H}_{6} \mathrm{O}_{3}$ \\
\hline 43 & Acetone, acetaldehyde, acetic acid & $\mathrm{C}_{3} \mathrm{H}_{6} \mathrm{O}, \mathrm{C}_{2} \mathrm{H}_{4} \mathrm{O}, \mathrm{C}_{2} \mathrm{H}_{4} \mathrm{O}_{2}$ \\
\hline 44 & Carbon dioxide, acetaldehyde & $\mathrm{CO}_{2}, \mathrm{C}_{2} \mathrm{H}_{4} \mathrm{O}$ \\
\hline 45 & Acetic acid, formic acid & $\mathrm{C}_{2} \mathrm{H}_{4} \mathrm{O}_{2}, \mathrm{HCOOH}$ \\
\hline 46 & Formic acid & $\mathrm{HCOOH}$ \\
\hline 53 & Methylfuran & $\mathrm{C}_{5} \mathrm{H}_{6} \mathrm{O}_{2}$ \\
\hline 57 & Levoglucosane & $\mathrm{C}_{6} \mathrm{H}_{10} \mathrm{O}_{5}$ \\
\hline 58 & Acetone & $\mathrm{C}_{3} \mathrm{H}_{6} \mathrm{O}$ \\
\hline 60 & Levoglucosane & $\mathrm{C}_{6} \mathrm{H}_{10} \mathrm{O}_{5}$ \\
\hline 68 & Furan & $\mathrm{C}_{4} \mathrm{H}_{4} \mathrm{O}$ \\
\hline
\end{tabular}

\section{Effect of cellulose source on the pyrolysis.}

We further selected HD and FD samples for the pyrolysis process of cellulose nanofibers originating from bacteria and algae (BCNF and ACNF, respectively) having a higher crystallinity index and larger crystal size than WCNF (Table 2). As expected, micrographs of the FD substrates show a highly porous structure compared to HD substrates (Figure 4). Interestingly, the sheets forming the FD substrate reveals the presence of individual fibrils for ACNF and BCNF samples that were barely visible for freeze-dried WCNF sample. The increase in crystal size of CNF thus prevents to some extent their aggregation as they become stiffer and less flexible (see TEM micrographs of various CNF in Figure 1), and this leads to interspace between fibrils when they are stacking. The greater mobility of WCNF on the other hand facilitates their dense packing. Subsequently, the $\mathrm{S}_{\mathrm{BET}}$ of the FD substrates increases with the increase in the crystal size of CNF (Table 2 and Supporting information S4). The same trend is observed for HD samples, i.e., $\mathrm{S}_{\mathrm{BET}}$ increases with the crystal size from a value of $0.1 \mathrm{~m}^{2} \mathrm{~g}^{-1}$ for WCNF to $64 \mathrm{~m}^{2} \mathrm{~g}^{-1}$ for ACNF giving more discernible fibrils in SEM micrographs (Figure 4, Table 2 and Supporting information S4). The BJH pore volume which takes into account pores up to $\sim 200 \mathrm{~nm}$ is supporting this observation, and increases with the increase in the crystal size of CNF (Table 2). 
SEM micrographs of the pyrolysed ACNF and BCNF samples reflect the structure prior to pyrolysis (Figure 4). We note that chars from HD samples display a larger $\mathrm{S}_{\mathrm{BET}}$ than chars from FD samples (Table 2). This can be attributed to the weaker mechanical properties of the FD substrates favouring nanofibers aggregation during pyrolysis, or to difference in fibrils arrangement in both substrates. Interestingly, for the same heat-drying, the corresponding char of ACNF has a much higher $\mathrm{S}_{\mathrm{BET}}$ than that of WCNF (361 $\left.\mathrm{m}^{2} \mathrm{~g}^{-1} \mathrm{vs} 7 \mathrm{~m}^{2} \mathrm{~g}^{-1}\right)$ and a BJH pore volume as high as $0.64 \mathrm{~cm}^{3} \mathrm{~g}^{-1}$ (Table 2), thus reflecting positive effect of large crystallites for structure preservation upon drying and pyrolysis.
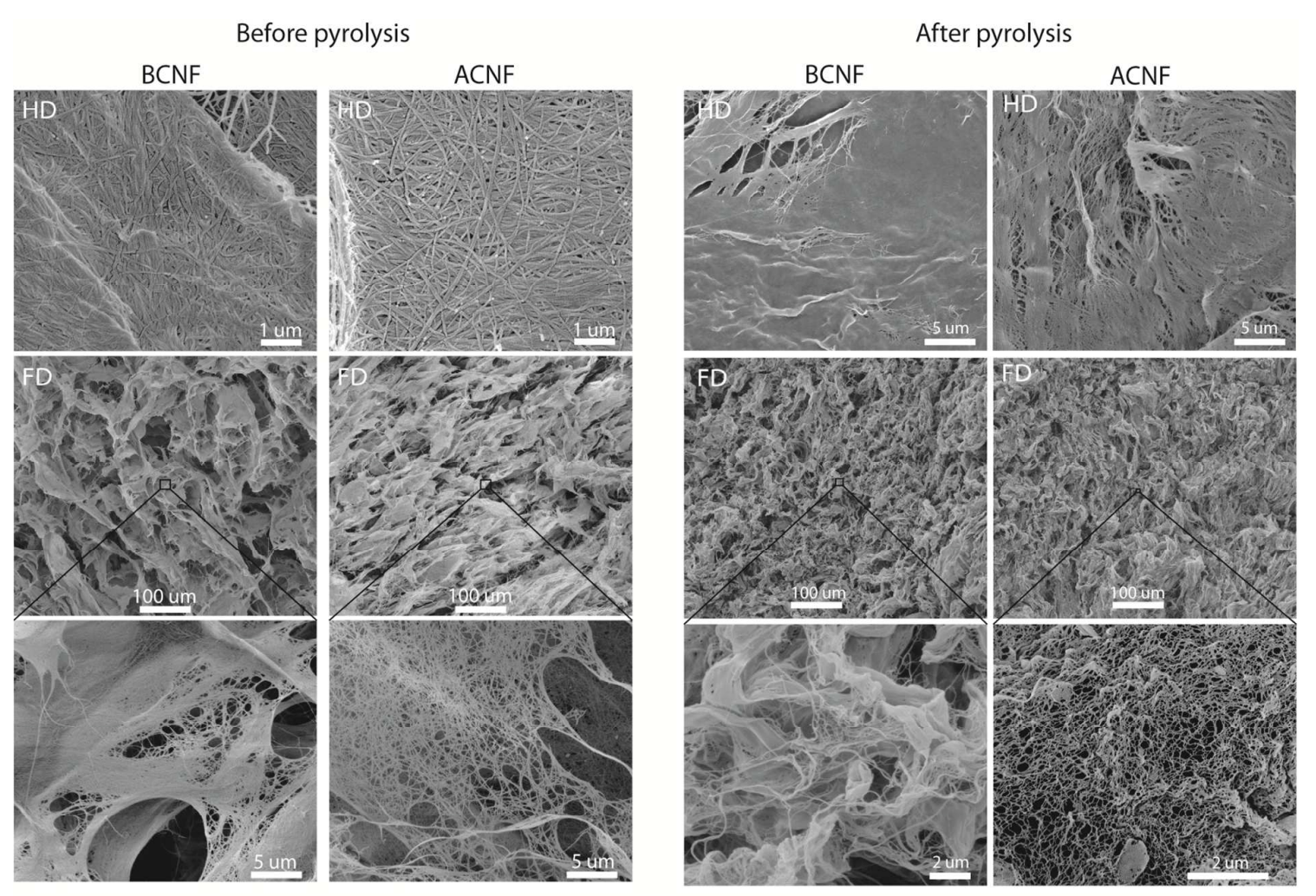

Figure 4. SEM micrographs of BCNF and ACNF substrates and their corresponding chars.

The effect of the CNF crystal size on their thermal degradation behaviour has been investigated by thermogravimetic analysis coupled with a mass-spectrometer. CNF with larger crystals show enhanced thermal stability leading to a difference of $60{ }^{\circ} \mathrm{C}$ between the $\mathrm{T}_{\text {onset }}$ of the freeze-dried WCNF and ACNF substrates (Figure 5.a, Table 2). Similarly, a difference of $40^{\circ} \mathrm{C}$ was observed between the $\mathrm{T}_{\text {onset }}$ of Funacel cellulose $\left(\mathrm{CI}=54 \% ; \mathrm{T}_{\text {onset }}=285^{\circ} \mathrm{C}\right)$ and Halocynthia cellulose $\left(\mathrm{CI}=74 \% ; \mathrm{T}_{\text {onset }}=325^{\circ} \mathrm{C}\right)$ as the crystal size shifted from $4.5 \mathrm{~nm}$ to $10.6 \mathrm{~nm}$, respectively. ${ }^{46}$ The reduction in cellulose crystallinity from $65 \%$ to $6.5 \%$ via ball-milling led also to a reduction in thermal degradation 
temperature in TGA graphs. ${ }^{59}$ Poletto et al. reported that thermal decomposition of wood shifted to higher temperatures with increasing wood cellulose crystallinity and crystallite size. ${ }^{91}$ All these results indicate that large cellulose crystals require a higher temperature to break their crystal structure, i.e., hydrogen bonds before weight loss takes place in the inner part of the crystal. ${ }^{46,59,91}$ The melting of ACNF crystals was clearly observed as an endothermic peak in DSC thermogram with a maximum at $380{ }^{\circ} \mathrm{C}$ for a heating rate of $10 \mathrm{~K} \mathrm{~min}^{-1}$, while melting of WCNF and BCNF crystals was less obvious in DSC thermograms, and may be maximum at $277{ }^{\circ} \mathrm{C}$ and $361{ }^{\circ} \mathrm{C}$, respectively (Supporting information S5). With the increase in the crystal size, volatiles emission during pyrolysis is also shifted to higher temperature (Figure 5.c; full spectra in Supporting information S3). The higher weight loss rate accompanying the increase in the crystal size of CNF (Figure 5.b) is attributed to the higher surface area minimizing volatiles retention.

For BCNF samples, a higher char yield is observed for the HD sample as compared to the FD sample due to nearly 5 times lower $\mathrm{S}_{\mathrm{BET}}\left(13 \mathrm{~m}^{2} \mathrm{~g}^{-1}\right.$ for HD vs $66 \mathrm{~m}^{2} \mathrm{~g}^{-1}$ for FD). In contrast, ACNF gives a similar char yield for both substrates due to a close $\mathrm{S}_{\mathrm{BET}}\left(64 \mathrm{~m}^{2} \mathrm{~g}^{-1}\right.$ for HD vs $86 \mathrm{~m}^{2} \mathrm{~g}^{-1}$ for FD) and less fibrils aggregation in both substrates. Furthermore, unlike heat-dried WCNF which expanded during heating, heat-dried ACNF and BCNF shrank upon heating (Figure 5.d) as they have a larger $\mathrm{S}_{\mathrm{BET}}$ than WCNF permitting vapours evacuation. 

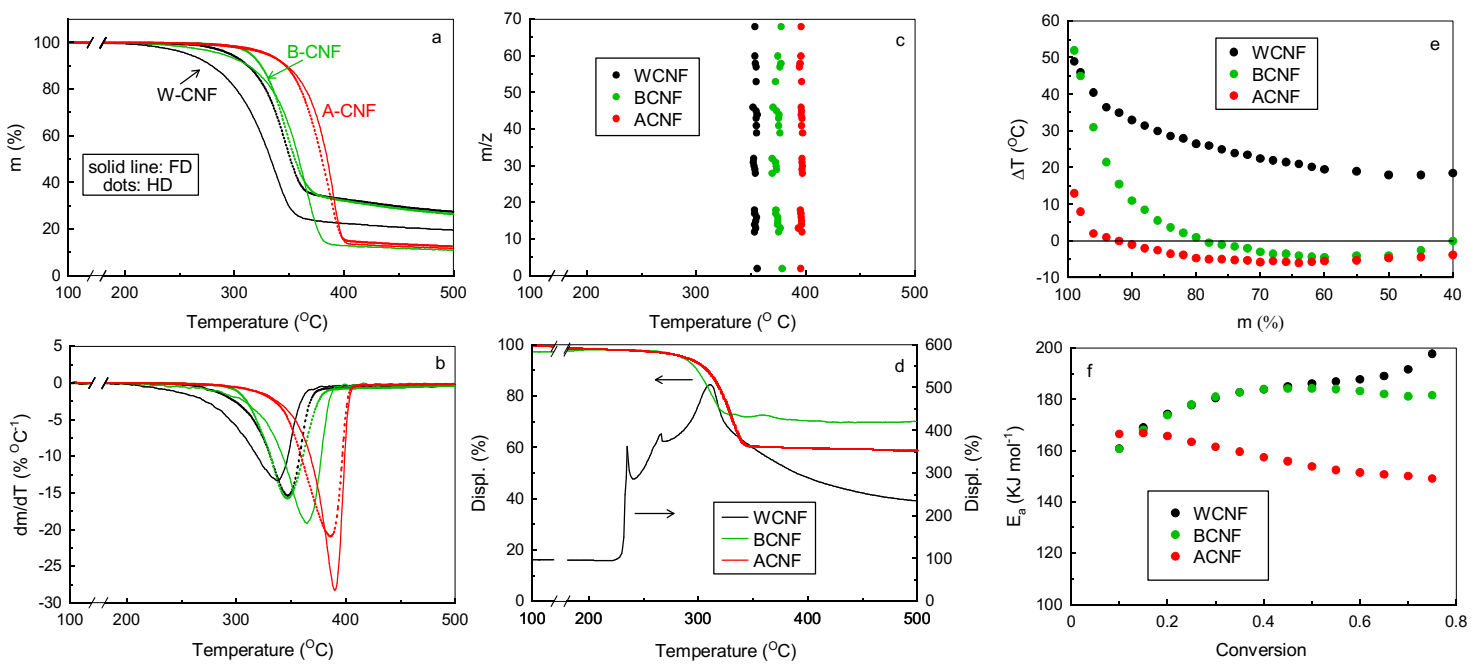

Figure 5.a. TGA, b. DTG, c. TG-MS signals vs their peak temperature, d. TMA, e. $\Delta \mathrm{T}$ vs weight and f. Activation energy $\left(E_{a}\right)$ vs conversion for various $C N F$.

We now analyse the difference between the thermal degradation of FD and HD substrates. The FD samples present a density more than 2 orders of magnitude lower than HD samples' density (Table 2), and this should give inside the substrate a different vapour pressure of the volatiles released during heating. As for WCNF, FD samples from BCNF and ACNF have a lower $\mathrm{T}_{\text {onset }}$ than HD counterparts (Table 2), attributed to a lower water vapour pressure in the former favouring dehydration. We denote the temperature difference between the HD and FD substrates for the same weight loss as $\Delta \mathrm{T}$. In the TGA graph (Figure 5.a) and in the graph showing $\Delta \mathrm{T}$ as a function of the weight (Figure 5.e), it is interesting to note that, unlike WCNF, $\triangle \mathrm{T}$ for BCNF and ACNF nullify at temperatures of $336{ }^{\circ} \mathrm{C}$ and $342{ }^{\circ} \mathrm{C}$ corresponding to a weight loss of $21 \%$ and $8 \%$, respectively. We expect these values to correspond to the consumption of the amorphous part of BCNF and ACNF. Subsequent to $\triangle T=0, H D$ and FD substrates being crystalline, show a similar degradation pattern with a slightly negative $\Delta \mathrm{T}$.

The apparent activation energy $\left(\mathrm{E}_{\mathrm{a}}\right)$ of the thermal decomposition of various heat-dried CNF was first analysed by the Ozawa method from the peak position in the DTG curves at heating rates of $1,2,5$ and $10{ }^{\circ} \mathrm{C} \mathrm{min}-1$ (Supporting information S5) ${ }^{60}$ In the Arrhenius plots showing the logarithms of heating rate versus reciprocal absolute temperature of DTG peak of three CNF samples (Supporting information S6), a good fit $\left(\mathrm{R}^{2}\right.$ values $\left.>0.99\right)$ was obtained for WCNF and BCNF with corresponding $E_{a}$ values of 200 and $205 \mathrm{KJ} \mathrm{mol}^{-1}$, respectively, versus $E_{a}=158 \mathrm{KJ} \mathrm{mol}^{-1}$ for ACNF. We thereafter 
determined the dependence of activation energy on the conversion using the isoconversional method by Starink (Figure 5.f). ${ }^{61}$ At a conversion of $\alpha=0.1$, the $E_{a}$ is similar for all sample (160.7166.6 $\mathrm{KJ} \mathrm{mol}^{-1}$ ), and might be associated with the thermal decomposition of the amorphous cellulose. With the increase in the conversion, $E_{a}$ for ACNF sample decreases reaching $149 \mathrm{KJ} \mathrm{mol}^{-1}$ at $\alpha=0.75$. In contrast, $\mathrm{E}_{\mathrm{a}}$ for WCNF increases with the conversion to a maximum value of $198 \mathrm{KJ} \mathrm{mol}^{-1}$ at $\alpha=0.75$, while $\mathrm{E}_{\mathrm{a}}$ for BCNF increases to $184 \mathrm{KJ} \mathrm{mol}^{-1}$ at $\alpha=0.5$ then stabilizes somewhat at this value. In the work by Kim et al., similar activation energy of $\sim 160 \mathrm{KJ} \mathrm{mol}^{-1}$ (from Ozawa method) was reported for native cellulose nanofibers of the same crystal type from Funacel, cotton, and Halocynthia sources, although no information on the structure of the samples was reported. ${ }^{46}$ It was concluded that the crystallite size does not affect the activation energy of the thermal degradation. Ornaghi Jr. et al. found that the activation energies for six different vegetal fibers are similar and do not correlate with the crystalline content. ${ }^{92}$ In the present work, we attribute higher $\mathrm{E}_{\mathrm{a}}$ for WCNF and BCNF samples as compared to $\mathrm{E}_{\mathrm{a}}$ of ACNF to the additional formation of a secondary char in these samples whereby fibrils aggregation is considerable. After comparing the $\mathrm{E}_{\mathrm{a}}$ of heat-dried and freeze-dried WCNF, we found a lower $E_{a}$ for the FD sample that we associate to easy evacuation of thermal degradation products during pyrolysis of the FD sample (Supporting information S6). We concluded that the structure of the sample (density and surface area) influences its thermal decomposition activation energy. This is in line with observations by Milosavljevic and Suuberg who reported that lower activation energy values are generally found for short residence time of volatiles during pyrolysis corresponding to the fast pyrolysis process. ${ }^{62}$

\section{Possible thermal degradation pathway of cellulose nanofibers under slow pyrolysis.}

Initially, cellulose is composed by amorphous and crystalline fractions with a higher reactivity and faster kinetic of thermal decomposition of the former. The thermal degradation starts once the glass transition temperature of cellulose $\left(\sim 210^{\circ} \mathrm{C}\right)^{63}$ has been surpassed permitting chains rearrangement and dehydration of cellulose mostly occurring in the amorphous part of cellulose. ${ }^{64}$ An intramolecular dehydration mechanism of cellulose starting from $220^{\circ} \mathrm{C}$ has been suggested by Scheirs et al. after their FTIR study revealed new $\mathrm{C}=\mathrm{C}$ and $\mathrm{C}=\mathrm{O}$ stretching vibrations at this temperature. ${ }^{56,65,66}$ The first 
expansion of WCNF at $220^{\circ} \mathrm{C}$ is thus attributed to cellulose dehydration via the chemical elimination of water molecules. The released water combined with the elevated temperature then depolymerizes/hydrolyses the amorphous cellulose chains (the crystals being impermeable to water) leading first to oligo-sugars and to single sugar molecules, which were identified by Lin et al. using HPLC to correspond to $\mathrm{DP}=2-7$ sugars and to levoglucosan $(\mathrm{DP}=1) .{ }^{67}$ The TMA expansion is subsequently followed by an abrupt contraction of the substrate that may possibly come from crosslinking of the structure via intermolecular dehydration of cellulose/oligomers, further leading to a primary char which retains the structure of the starting CNF material. ${ }^{59,64,68-72}$ In the TMA graph, the second expansion at $240{ }^{\circ} \mathrm{C}$ indicates a subsequent release of other vapors possibly emanating from the dehydration of oligomers and levoglucosan forming intermediate sugars. ${ }^{67}$ These fragmentizes after C$\mathrm{O}$ and $\mathrm{C}-\mathrm{C}$ bonds break giving volatiles and light gases that were identified by TG-MS (Table 3), and that may contribute to the third expansion of WCNF at $270{ }^{\circ} \mathrm{C} .{ }^{73}$ Based on density functional theory calculations, Zhang et al. found that acetaldehyde $(\mathrm{m} / \mathrm{z}=44)$ and carbon monoxide $(\mathrm{m} / \mathrm{z}=28)$ can be formed from the $\mathrm{C}-\mathrm{O}$ bond breaking reactions of levoglucosan, while 1,2-Dihydroxyethene $(\mathrm{m} / \mathrm{z}=60)$ can be formed from the C-C bond breaking reactions. ${ }^{74}$ Other products such as hydrogen $(\mathrm{m} / \mathrm{z}=2)$, methane $(\mathrm{m} / \mathrm{z}=16)$, carbon monoxide and dioxide $(\mathrm{m} / \mathrm{z}=28,44)$, formaldehyde $(\mathrm{m} / \mathrm{z}=30)$, acetaldehyde $(\mathrm{m} / \mathrm{z}=44)$, glycolaldehyde $(\mathrm{m} / \mathrm{z}=60)$, methanol $(\mathrm{m} / \mathrm{z}=32)$, ethanol $(\mathrm{m} / \mathrm{z}=46)$ and acetone $(\mathrm{m} / \mathrm{z}=58)$ may form according to the degradation routes of cellulose/levoglucosan proposed by Shen et al. ${ }^{75}$ These volatiles, when trapped between the fibrils, e.g., for low $\mathrm{S}_{\mathrm{BET}}$ substrates, will condense into an additional "secondary char", although the two char types may have similar reactivity ${ }^{76,77}$ and composition (Supporting information S2). Provided the cellulose crystals have not broken apart during thermal decomposition of amorphous cellulose, the consumption of the amorphous part of cellulose will then lead to a low DP crystalline cellulose so-called active cellulose. ${ }^{65,78-80}$

The thermal degradation of crystalline cellulose cannot start unless the hydrogen bonds in the crystal have been broken, which releases free "amorphous" cellulose chains. This is in agreement with computational work in which the importance of the interchain hydrogen bonds in the thermal degradation process of cellulose has been highlighted, showing that the glucosyl moiety inside the 
cellulose crystal is considerably more stable and that the thermal degradation occurs selectively on the surface of the cellulose crystal. ${ }^{81}$ We expect two scenarios to occur depending on the crystal size of cellulose. Melting of small crystals will occur at relatively low temperature whereby the free cellulose chains undergo the same degradation pathway of the initial amorphous phase, i.e., dehydration followed by hydrolysis and fragmentation. This leads to a positive $\Delta \mathrm{T}$ for both the amorphous and crystalline phases (WCNF in Figure 5.e). On the other hand, melting of large crystals occurs at a high temperature whereby fragmentation via bonds scission should be dominant. This would then nullify $\triangle \mathrm{T}$ for ACNF and BCNF samples once the amorphous part has been consumed, subsequently leading to a slightly negative $\Delta \mathrm{T}$ that might come from exothermic effect of bond scission. ${ }^{77,82-84}$ Breakage of the glucosidic $\mathrm{C}-\mathrm{O}$ bond would lead to levoglucosan, whose fragmentation via other $\mathrm{C}-\mathrm{O}$ and $\mathrm{C}-$ C breakage would lead to volatiles and light gases,${ }^{74}$ that can eventually form a secondary char when trapped within the substrate. The proposed thermal degradation pathway of CNF under slow pyrolysis is illustrated in Figure 6. Note that this pathway shares similarities with cellulose hydrolysis in hot compressed water, in which oligomers are first formed in the amorphous portion of cellulose, then in the crystalline portion once the hydrogen bonds in crystalline cellulose have been broken to make the glycosidic bonds accessible to the hot compressed water. ${ }^{85}$

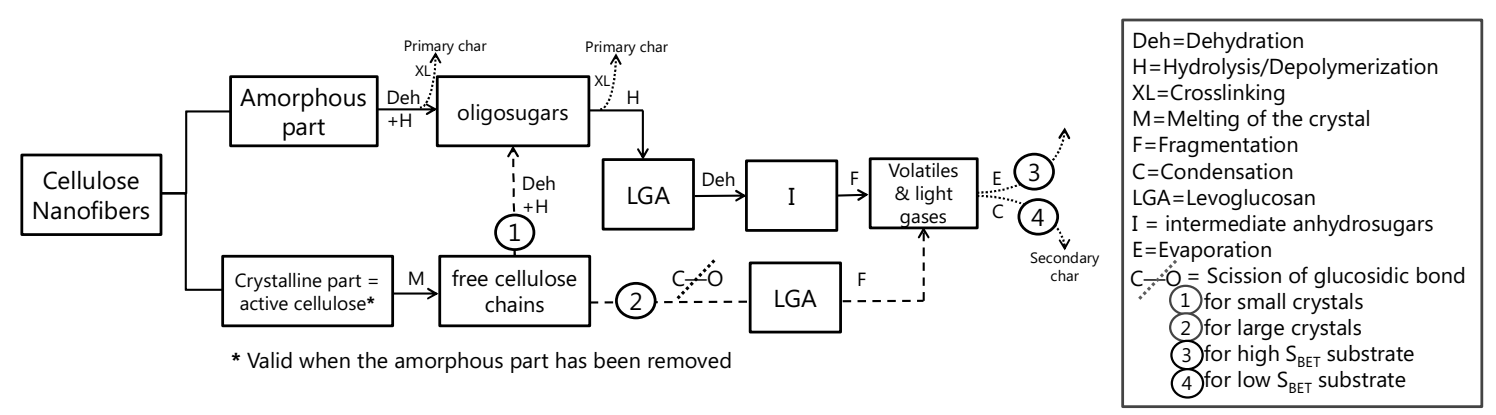

Figure 6. Proposed thermal decomposition pathway of CNF under slow pyrolysis.

\section{Oil absorption by the chars}

The pyrolysis process of CNF is accompanied by a loss of samples' crystallinity (Supporting information S7), an increase in their carbon content (Supporting information S2), and a reduction in their moisture uptake (Supporting information S8), which results in CNF chars with enhanced hydrophobicity. The ability of CNF char to absorb non-polar liquids was first tested by immersing it 
in a water bath containing dodecane. This latter was rapidly sucked by the char leading to a clean water surface (Figure 7.a). We thereafter investigated density effect of the CNF substrate (related to its porosity) on the absorption capacity of its char. WCNF substrates were prepared by heat-drying or by freeze-drying aqueous WCNF suspensions of various concentrations leading to CNF substrates having various densities, as reported in our previous work. ${ }^{35}$ The corresponding chars were used for the uptake of various oils and organic solvents. Figure 7.b shows that the absorption capacity of the pyrolysed HD substrate is quite low $\left(6-22 \mathrm{~g} \mathrm{~g}^{-1}\right)$ which is attributed to its low porosity (see SEM micrograph in Figure 2). The pyrolysed FD substrates of low density have on the other hand a higher absorption capacity up to $100 \mathrm{~g} \mathrm{~g}^{-1}$ due to their higher porosity permitting liquid uptake (Figure 2). Interestingly, there is an optimum density of the WCNF, around $5 \mathrm{~kg} \mathrm{~m}^{-3}$, giving a char with the best absorption performance. Even lower density of the WCNF did not necessarily lead to a higher absorption capacity of the corresponding char possibly due to weak mechanical properties leading to contraction of the char upon liquid uptake. Such phenomenon has already been observed by Cervin et al. who found that low density silylated CNF aerogels are more prone to collapse upon hexadecane uptake compared to their higher density counterparts. ${ }^{18}$ Amongst various liquids, the highest absorption capacity was reached for chloroform due to its higher density as compared to density of other liquids $\left(\rho_{\mathrm{CHCl}}=1.49 \mathrm{~g} \mathrm{~cm}^{-3}\right.$ vs $\rho_{\text {other liquids }}=0.75-0.95 \mathrm{~g} \mathrm{~cm}^{-3}$ ). The high density of chloroform would have probably led to higher capillary forces on the chars during the absorption process leading to an optimum density of $15 \mathrm{~kg} \mathrm{~m}^{-3}$ (see arrow in Figure 7.b).

We thereafter compare the chars' performance corresponding to freeze-dried WCNF, BCNF and ACNF with a density of $5 \mathrm{~kg} \mathrm{~m}^{-3}$ (Figure 7.b). In most cases, chars from BCNF performed the best with an adsorption capacity of $64-120 \mathrm{~g} \mathrm{~g}^{-1}$ for various liquids versus $55-95 \mathrm{~g} \mathrm{~g}^{-1}$ for chars from WCNF, while ACNF gives the lowest uptake of $26 \mathrm{~g} \mathrm{~g}^{-1}$ for motor oil. After normalizing the weight uptake with respect to the density of various liquids, it becomes apparent that pore volume used for the liquid uptake is far lower for ACNF $\left(31.5 \mathrm{~cm}^{3} \mathrm{~g}^{-1}\right)$ as compared to WCNF $\left(63-83 \mathrm{~cm}^{3} \mathrm{~g}^{-1}\right)$ and BCNF $\left(68-118 \mathrm{~cm}^{3} \mathrm{~g}^{-1}\right)$ (Figure 7.c). Since the absorption capacity depends on a number of parameters such 
as the polarity of the liquid, the oleophilicity, pore size and volume, and mechanical strength of the char, these parameters are optimized in BCNF char giving the highest absorption capacity.

Compared to other oil/solvent sorbents reported in the literature, the char prepared herein from freezedried $\mathrm{BCNF}$ at a pyrolysis temperature of $500{ }^{\circ} \mathrm{C}$ has a similar capacity compared to $\mathrm{BCNF}$ pyrolysed at $1450{ }^{\circ} \mathrm{C}$ or to cotton pyrolysed at $800^{\circ} \mathrm{C}, 2^{22,86}$ and higher capacity than char prepared from recycled newspaper at a pyrolysis temperature of $900{ }^{\circ} \mathrm{C}\left(12-22 \mathrm{~g} \mathrm{~g}^{-1}\right)$ (Figure $\left.7 . \mathrm{d}\right){ }^{87}$ This indicates that higher pyrolysis temperature above $500{ }^{\circ} \mathrm{C}$ does not necessarily lead to higher solvent/oil uptake. Compared to $\mathrm{CNF} /$ inorganic hybrids, the present $\mathrm{BCNF}$ char has similar adsorption capacity as MTMS/CNF, ${ }^{19}$ higher capacity than $\mathrm{TiO}_{2}$ coated CNF aerogel $\left(20-40 \mathrm{~g} \mathrm{~g}^{-1}\right),{ }^{17}$ and lower capacity than silane-modified CNF aerogel $\left(190-350 \mathrm{~g} \mathrm{~g}^{-1}\right){ }^{88}$ 

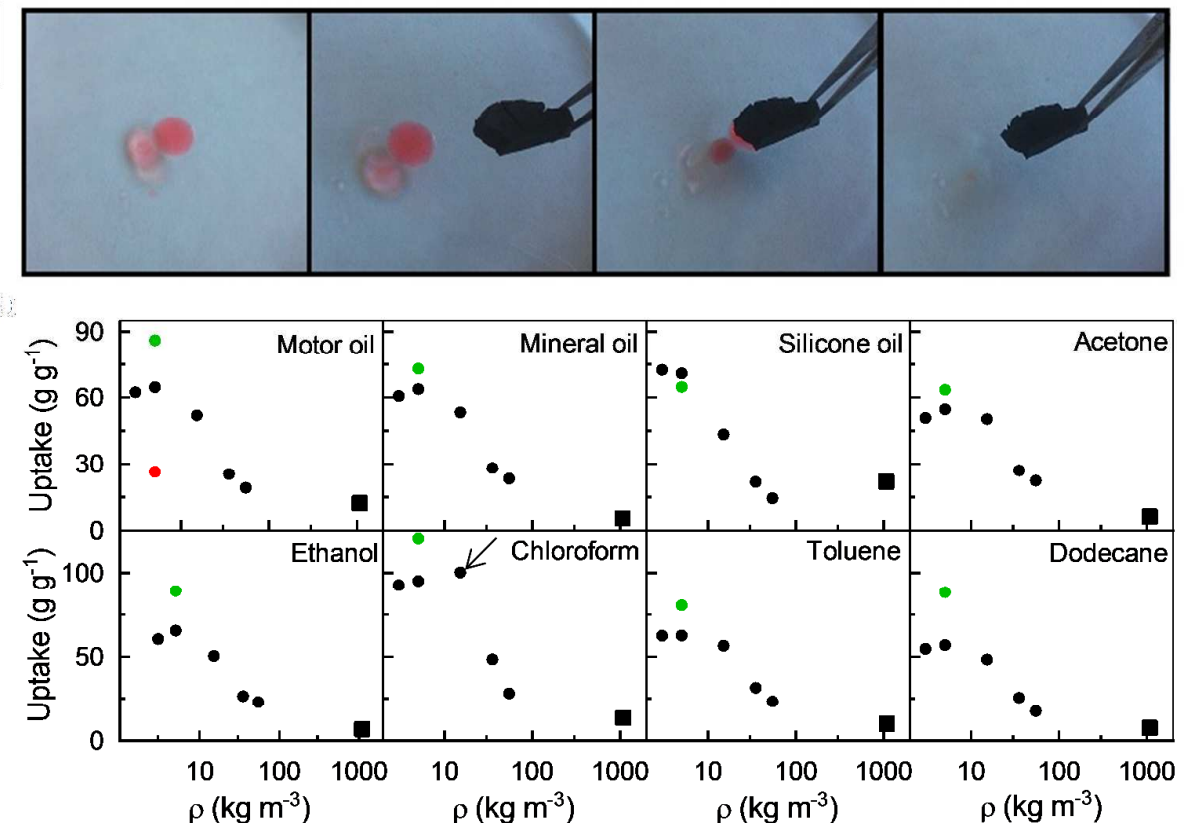

\section{c}

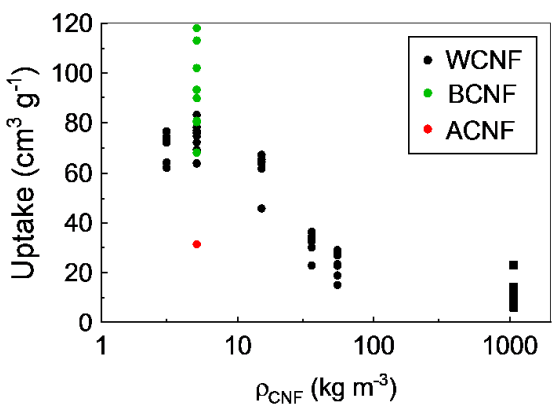

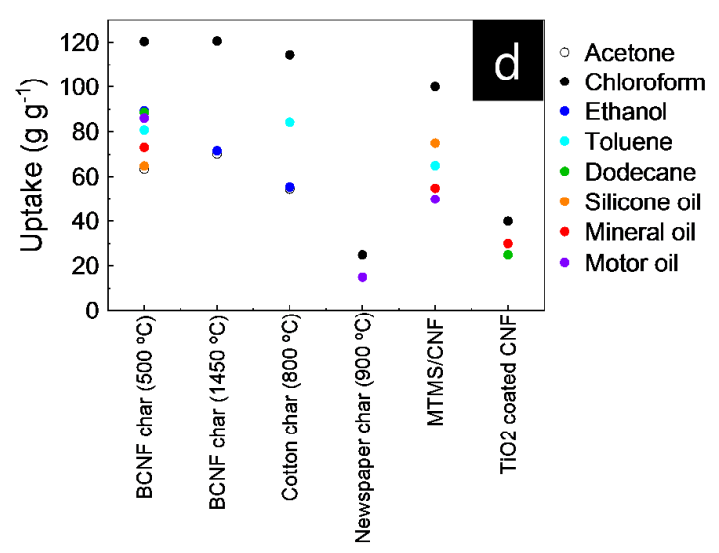

Figure 7.a. Photograph showing dodecane removal by freeze-dried WCNF's char. b. Oil/solvent uptake by weight versus density of CNF substrate. The square and the circles correspond to chars from HD and FD samples, respectively. Black, green and red indicate WCNF, BCNF and ACNF, respectively. c. Oil/solvent uptake by volume versus density of CNF substrate. d. Comparison of oil/solvent uptake of the present BCNF char (dots in left) with other sorbents cited in the liteature (data extracted from graphs).

\section{Dye adsorption}

The high surface area of the chars can be exploited for the adsorption of non-polar species. This is illustrated herein by the adsorption of 3 organic dyes, namely, methylene blue, congo red and crystal violet. Chars obtained from pyrolysis of WCNF substrates were first selected for the adsorption of a cationic methylene blue (MB) dye. As compared to chars prepared from WCNF dried from water, chars prepared from WCNF dried from solvent display a higher MB removal capacity and faster kinetic of adsorption attributed to their high $\mathrm{S}_{\mathrm{BET}}$ values (Figure 8.a,d,e). The char corresponding to 
freeze-dried WCNF permits a 98\% removal of MB solution having a concentration of $4 \mathrm{mg} \mathrm{L}^{-1}$, but its efficiency decreases to $43 \%$ for a ten-fold more concentrated MB solution (Figure 8.b,e). The increase in the $\mathrm{S}_{\mathrm{BET}}$ of the WCNF char enhances the number of sites available for the adsorption of MB permitting the treatment of such concentrated MB solution, i.e., the SCD char can remove $99.8 \%$ of $\mathrm{MB}$ at a concentration of $40 \mathrm{mg} \mathrm{L}^{-1}$ (Figure 8.b,e). The maximum amount of MB adsorbed increases with the $\mathrm{S}_{\mathrm{BET}}$ of the WCNF char going from $0.6 \mathrm{mg} \mathrm{g}^{-1}$ for HD to $43.7 \mathrm{mg} \mathrm{g}^{-1}$ for SCD chars (Figure 8.c). Moreover, the chars prepared from solvent-dried WCNF have a good removal capacity for crystal violet (CV; cationic dye) and congo red (CR; anionic dye), with a maximum capacity of $48 \mathrm{mg} \mathrm{g}^{-1}$ and $158 \mathrm{mg} \mathrm{g}^{-1}$, respectively (Figure 8.c). WCNF chars have seemingly a better affinity for anionic dyes, probably due to specific interactions between the two components.

MB adsorption by chars originating from various heat-dried CNF was investigated. These chars present a dense structure (Figure 4) and $\mathrm{S}_{\mathrm{BET}}$ values of 7, 196 and $361 \mathrm{~m}^{2} \mathrm{~g}^{-1}$ for WCNF, BCNF and $\mathrm{ACNF}$, respectively. Despite their dense structure and due to their high $\mathrm{S}_{\mathrm{BET}}$, BCNF and ACNF chars present a higher MB removal capacity compared to WCNF char. The adsorption process is however slow and is probably hindered by the dense structure of the chars where accessibility to the dye molecule is reduced. For a MB concentration of $40 \mathrm{mg} \mathrm{L}^{-1}$, the $\%$ removal after 1 month of contact between the dye and the char is $19 \%$ and $78 \%$ for the BCNF and ACNF chars respectively, while it is negligible for the WCNF char. The corresponding adsorption capacities at this concentration are 6.3 and $28.4 \mathrm{mg} \mathrm{g}^{-1}$, for BCNF and ACNF chars, respectively. This further confirms positive effects of large CNF crystallites giving chars with large $\mathrm{S}_{\mathrm{BET}}$ and good dye adsorption capacity. 

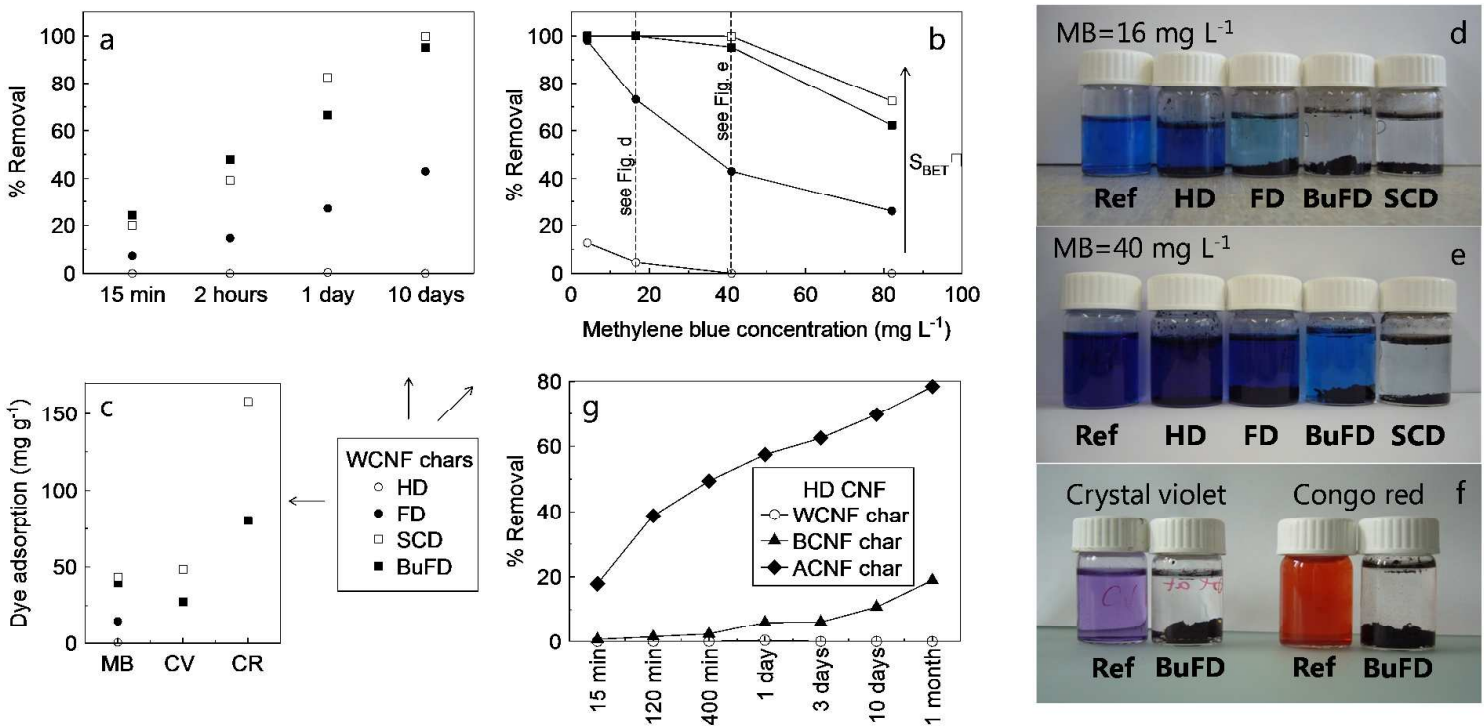

Figure 8.a. \% Methylene blue (MB) removal by WCNF chars at different time intervals. MB concentration is $40 \mathrm{mg} \mathrm{L}^{-1}$. b. \% MB removal by WCNF chars for various MB concentrations. c. Maximum dye adsorption capacity of WCNF chars. The capacity was determined for a MB, CV and CR concentrations of 80,50 and $100 \mathrm{mg} \mathrm{L}^{-1}$. d\&e. Photographs of MB solution after dye adsorption by WCNF chars. Ref corresponds to the MB solution alone. MB concentration is given in top left of each picture. f. Photograph of crystal violet (CV) and congo red (CR) solutions after dye adsorption by WCNF char. g. \% MB removal by chars from various $\mathrm{CNF}$ vs time of contact. MB concentration is $40 \mathrm{mg} \mathrm{L}^{-1}$.

\section{Conclusions}

Native cellulose nanofibers with various crystal sizes originating from wood, bacteria and algae were prepared as aqueous gels, and subsequently dried via different routes giving various CNF substrates. In the first part, thermal properties of wood CNF were found to depend on their structure, which is in turn affected by the CNF drying. The following conclusions were drawn:

- The temperature at the onset of thermal degradation of the CNF substrate depends on its density and is higher for denser samples. This might be associated with higher vapour pressure of the decomposition products inside these samples which inhibits further degradation.

- CNF substrates dried from water present a lower specific surface area compared to those dried from solvents as a result of fibrils aggregation. Consequently, they present a higher char yield and a lower weight loss rate as the thermal decomposition products are trapped within the aggregated fibrils leading to a secondary char.

- The pyrolysis is accompanied by dimensional changes of the substrate. Substrates presenting some surface area shrink upon pyrolysis and the shrinkage correlates with the char yield. In 
contrast, CNF film prepared via heat-drying does not display an internal surface area and expanded during pyrolysis due to stresses from emitted volatiles. Three expansions were identified for this sample at $\sim 220^{\circ} \mathrm{C}, 240{ }^{\circ} \mathrm{C}$ and $270{ }^{\circ} \mathrm{C}$ reflecting three main stages of thermal decomposition of wood CNF leading to vapour release.

- After pyrolysis, the structure of the obtained char is similar to the original CNF substrate. When the CNF substrate has a low density and a high specific surface area, nanofibers aggregation during pyrolysis is expected due to the weak mechanical properties of the substrate which cannot counteract thermal stresses.

In the second part, the effects of cellulose source on CNF structure and thermal properties were investigated. The following observations were made:

- CNF with larger crystallites form substrates with higher specific surface area upon drying from aqueous suspension as they are straight and rigid permitting fibrils interspace while stacking. The corresponding chars also display a large $\mathrm{S}_{\mathrm{BET}}$.

- The increase in the crystal size of the CNF is accompanied by an increased thermal stability. Larger crystals require a higher temperature to break their hydrogen bonds before thermal degradation takes place in the inner part of the crystal.

- For CNF displaying large crystals, there are two distinct thermal degradation zones. The initial thermal degradation is associated with the amorphous phase and occurs at higher temperature for denser samples. The subsequent thermal degradation associated with the crystalline phase does not show a substantial dependence on the sample's density. This indicates a different thermal degradation pathway for the amorphous and crystalline portions of these CNF. The thermal degradation of the amorphous cellulose would be facilitated by the dehydration of the chains leading first to their depolymerization and then to further fragmentation of the sugars. The crystalline phase decomposes after the crystal melts. Large crystals display a high melting temperature at which chains fragmentation via bonds scission would be dominant mechanism of thermal decomposition.

- The activation energy $\left(\mathrm{E}_{\mathrm{a}}\right)$ of the thermal decomposition of CNF determined according to the isoconversion method is clearly affected by the structure of the sample and varies with the 
conversion. Low density CNF have a low $\mathrm{E}_{\mathrm{a}}$ that might be associated with low vapour pressure in these samples during pyrolysis. Low surface area samples displaying fibrils aggregation have a high $\mathrm{E}_{\mathrm{a}}$ at high conversions which might be associated with the formation of a secondary char in these samples.

In the third part, the adsorption/absorption properties of various chars were investigated. It was concluded that:

- For oil/solvent absorption, chars displaying a high pore volume are desired. These could be achieved by freeze-drying CNF suspension of low concentration prior to pyrolysis. The optimum density of the CNF substrate giving chars with the highest absorption capacity was $5 \mathrm{~kg} \mathrm{~m}^{-3}$. Chars corresponding to the lowest density of the CNF $\left(3 \mathrm{~kg} \mathrm{~m}^{-3}\right)$ most probably shrank upon liquid uptake leading to a lower absorption capacity. When comparing the absorption capacity of chars from various CNF sources, it is found that the one from bacterial CNF offers the highest absorption capacity (64-120 $\mathrm{g} \mathrm{g}^{-1}$ ) corresponding to a pore volume for the oil/solvent uptake as high as $68-118 \mathrm{~cm}^{3} \mathrm{~g}^{-1}$. Bacterial CNF produces thus chars with optimum properties in terms of oleophilicity, pore size and volume, and mechanical strength.

- For dye adsorption, chars displaying a large specific surface area which is accessible to the dye molecule are desired. Conventional heat-drying of wood CNF aqueous suspension results in a substrate with negligible surface area whose pyrolysis led to a char with poor adsorption capacity towards methylene blue (MB) of $0.6 \mathrm{mg} \mathrm{g}^{-1}$ and a removal capacity of only $13 \%$ for a $4 \mathrm{mg} \mathrm{L}^{-1} \mathrm{MB}$ solution. On the other hand, drying wood CNF from solvents substantially enhances their surface area and that of the corresponding char. The char obtained via pyrolysis of supercritically dried wood CNF can remove $99.8 \%$ of a MB solution having a concentration of $40 \mathrm{mg} \mathrm{L}^{-1}$ and have maximum adsorption capacities of $44-158 \mathrm{mg} \mathrm{g}^{-1}$ towards methylene blue, crystal violet and congo red. When comparing the dye adsorption capacity of chars from various heat-dried CNF suspensions, those from algae CNF displayed superior performance as a result of their larger $\mathrm{S}_{\mathrm{BET}}$.

\section{ASSOCIATED CONTENT}

\section{Supporting Information}


Elemental analysis, TG-MS spectra, TGA, DTG and DSC graphs at various heating rates, XRD spectra and dynamic vapor sorption analysis. This material is available free of charge via the Internet at http://pubs.acs.org.

\section{Acknowledgements}

Anja Huch, Esther Strub, Beatrice Fischer, Arndt Remhof and Michael Schneider are thanked for their support for SEM, TEM, TGA, XRD and elemental analyses. Dr. Christopher Robinson from EAWAG is thanked for valuable advices and assistance in identifying and harvesting Cladophora algae.

\section{References:}

1. Schwarzenbach, R. P.; Escher, B. I.; Fenner, K.; Hofstetter, T. B.; Johnson, C. A.; von Gunten, U.; Wehrli, B., The Challenge of Micropollutants in Aquatic Systems. Science 2006, 313, (5790), $1072-1077$.

2. Shannon, M. A.; Bohn, P. W.; Elimelech, M.; Georgiadis, J. G.; Marinas, B. J.; Mayes, A. M., Science and technology for water purification in the coming decades. Nature 2008, 452, (7185), 301310.

3. Carpenter, A. W.; de Lannoy, C.-F.; Wiesner, M. R., Cellulose Nanomaterials in Water Treatment Technologies. Environ. Sci.Technol. 2015, 49, (9), 5277-5287.

4. Liu, P.; Sehaqui, H.; Tingaut, P.; Wichser, A.; Oksman, K.; Mathew, A., Cellulose and chitin nanomaterials for capturing silver ions (Ag+) from water via surface adsorption. Cellulose 2014, 21, (1), 449-461.

5. Sehaqui, H.; de Larraya, U.; Liu, P.; Pfenninger, N.; Mathew, A.; Zimmermann, T.; Tingaut, P., Enhancing adsorption of heavy metal ions onto biobased nanofibers from waste pulp residues for application in wastewater treatment. Cellulose 2014, 21, (4), 2831-2844.

6. Pei, A.; Butchosa, N.; Berglund, L. A.; Zhou, Q., Surface quaternized cellulose nanofibrils with high water absorbency and adsorption capacity for anionic dyes. Soft Matter 2013, 9, (6), $2047-$ 2055.

7. Ma, H. Y.; Burger, C.; Hsiao, B. S.; Chu, B., Nanofibrous Microfiltration Membrane Based on Cellulose Nanowhiskers. Biomacromolecules 2012, 13, (1), 180-186. 
8. Ma, H. Y.; Hsiao, B. S.; Chu, B., Ultrafine Cellulose Nanofibers as Efficient Adsorbents for Removal of $\mathrm{UO}_{2}{ }^{2+}$ in Water. ACS Macro Lett. 2012, 1, (1), 213-216.

9. Sehaqui, H.; Perez de Larraya, U.; Tingaut, P.; Zimmermann, T., Humic acid adsorption onto cationic cellulose nanofibers for bioinspired removal of copper(ii) and a positively charged dye. Soft Matter 2015, 11, (26), 5294-5300.

10. Sehaqui, H.; Mautner, A.; Perez de Larraya, U.; Pfenninger, N.; Tingaut, P.; Zimmermann, T., Cationic cellulose nanofibers from waste pulp residues and their nitrate, fluoride, sulphate and phosphate adsorption properties. Carbohydr. Polym. 2016, 135, 334-340.

11. Mautner, A.; Maples, H. A.; Sehaqui, H.; Zimmermann, T.; Perez de Larraya, U.; Mathew, A. P.; Lai, C. Y.; Li, K.; Bismarck, A., Nitrate removal from water using a nanopaper ion-exchanger. Environ. Sci: Water Res.Technol. 2016, 2, 117-124.

12. Sehaqui, H.; Gálvez, M. E.; Becatinni, V.; cheng Ng, Y.; Steinfeld, A.; Zimmermann, T.; Tingaut, P., Fast and Reversible Direct $\mathrm{CO}_{2}$ Capture from Air onto All-Polymer Nanofibrillated Cellulose-Polyethylenimine Foams. Environ. Sci. Technol. 2015, 49, (5), 3167-3174.

13. Gebald, C.; Wurzbacher, J. A.; Tingaut, P.; Zimmermann, T.; Steinfeld, A., Amine-Based Nanofibrillated Cellulose As Adsorbent for $\mathrm{CO}_{2}$ Capture from Air. Environ. Sci. Technol. 2011, 45, (20), 9101-9108.

14. Sehaqui, H.; Zimmermann, T.; Tingaut, P., Hydrophobic cellulose nanopaper through a mild esterification procedure. Cellulose 2014, 21, (1), 367-382.

15. Jonoobi, M.; Harun, J.; Mathew, A. P.; Hussein, M. Z. B.; Oksman, K., Preparation of cellulose nanofibers with hydrophobic surface characteristics. Cellulose 2010, 17, (2), 299-307.

16. Rodionova, G.; Lenes, M.; Eriksen, O.; Gregersen, O., Surface chemical modification of microfibrillated cellulose: improvement of barrier properties for packaging applications. Cellulose 2011, $18,(1), 127-134$

17. Korhonen, J. T.; Kettunen, M.; Ras, R. H. A.; Ikkala, O., Hydrophobic Nanocellulose Aerogels as Floating, Sustainable, Reusable, and Recyclable Oil Absorbents. ACS Appl. Mater. Inter. 2011, 3, (6), 1813-1816. 
18. Cervin, N. T.; Aulin, C.; Larsson, P. T.; Wagberg, L., Ultra porous nanocellulose aerogels as separation medium for mixtures of oil/water liquids. Cellulose 2012, 19, (2), 401-410.

19. Zhang, Z.; Sèbe, G.; Rentsch, D.; Zimmermann, T.; Tingaut, P., Ultralightweight and Flexible Silylated Nanocellulose Sponges for the Selective Removal of Oil from Water. Chem. Mater. 2014, 26, (8), 2659-2668.

20. Chin, S. F.; Binti Romainor, A. N.; Pang, S. C., Fabrication of hydrophobic and magnetic cellulose aerogel with high oil absorption capacity. Mater. Lett. 2014, 115, 241-243.

21. Meng, Y.; Young, T. M.; Liu, P.; Contescu, C. I.; Huang, B.; Wang, S., Ultralight carbon aerogel from nanocellulose as a highly selective oil absorption material. Cellulose 2014, 22, (1), 435447.

22. Wu, Z.-Y.; Li, C.; Liang, H.-W.; Zhang, Y.-N.; Wang, X.; Chen, J.-F.; Yu, S.-H., Carbon nanofiber aerogels for emergent cleanup of oil spillage and chemical leakage under harsh conditions. Sci. Rep. 2014, 4, 4079.

23. Wigmans, T., Proceedings of the Conference on Porosity and Carbon materials: Measurements and applications Industrial aspects of production and use of activated carbons. Carbon 1989, 27, (1), $13-22$.

24. Alatalo, S.-M.; Pileidis, F.; Mäkilä, E.; Sevilla, M.; Repo, E.; Salonen, J.; Sillanpää, M.; Titirici, M.-M., Versatile Cellulose-Based Carbon Aerogel for the Removal of Both Cationic and Anionic Metal Contaminants from Water. ACS Appl. Mater. Inter. 2015, 7, (46), 25875-25883.

25. Chen, L.-F.; Huang, Z.-H.; Liang, H.-W.; Gao, H.-L.; Yu, S.-H., Three-Dimensional Heteroatom-Doped Carbon Nanofiber Networks Derived from Bacterial Cellulose for Supercapacitors. Adv. Funct. Mater. 2014, 24, (32), 5104-5111.

26. Gui, X.; Li, H.; Zhang, L.; Jia, Y.; Liu, L.; Li, Z.; Wei, J.; Wang, K.; Zhu, H.; Tang, Z.; Wu, D.; Cao, A., A Facile Route to Isotropic Conductive Nanocomposites by Direct Polymer Infiltration of Carbon Nanotube Sponges. ACS Nano 2011, 5, (6), 4276-4283.

27. Wang, L.; Schutz, C.; Salazar-Alvarez, G.; Titirici, M.-M., Carbon aerogels from bacterial nanocellulose as anodes for lithium ion batteries. RSC Adv. 2014, 4, (34), 17549-17554. 
28. Wu, Z.-Y.; Liang, H.-W.; Chen, L.-F.; Hu, B.-C.; Yu, S.-H., Bacterial Cellulose: A Robust Platform for Design of Three Dimensional Carbon-Based Functional Nanomaterials. Acc. Chem. Res. 2016, 49, (1), 96-105.

29. Turbak, A. F.; Snyder, F. W.; Sandberg, K. R., Microfibrillated cellulose, a new cellulose product: properties, uses, and commercial potential. J. Appl. Polym. Sci. 1983, 37, 815-827.

30. Mihranyan, A., Cellulose from Cladophorales Green Algae: From Environmental Problem to High-Tech Composite Materials. J. Appl. Polym. Sci. 2011, 119, (4), 2449-2460.

31. Klemm, D.; Kramer, F.; Moritz, S.; Lindstrom, T.; Ankerfors, M.; Gray, D.; Dorris, A., Nanocelluloses: A New Family of Nature-Based Materials. Angew. Chem., Int. Ed. 2011, 50, (24), $5438-5466$.

32. Iguchi, M.; Yamanaka, S.; Budhiono, A., Bacterial cellulose - a masterpiece of nature's arts. J. Mater. Sci. 2000, 35, (2), 261-270.

33. Osullivan, A. C., Cellulose: the structure slowly unravels. Cellulose 1997, 4, (3), 173-207.

34. Sehaqui, H. Nanofiber networks, aerogels and biocomposites based on nanofibrillated cellulose from wood. PhD thesis, Royal Institute of Technology, Stockholm, 2011.

35. Sehaqui, H.; Salajkova, M.; Zhou, Q.; Berglund, L. A., Mechanical performance tailoring of tough ultra-high porosity foams prepared from cellulose I nanofiber suspensions. Soft Matter 2010, 6, (8), 1824-1832.

36. Sehaqui, H.; Liu, A. D.; Zhou, Q.; Berglund, L. A., Fast Preparation Procedure for Large, Flat Cellulose and Cellulose/Inorganic Nanopaper Structures. Biomacromolecules 2010, 11, (9), 2195-2198.

37. Sehaqui, H.; Zhou, Q.; Berglund, L. A., High-porosity aerogels of high specific surface area prepared from nanofibrillated cellulose (NFC). Compos. Sci. Technol. 2011, 71, (13), 1593-1599.

38. Sehaqui, H.; Zhou, Q.; Ikkala, O.; Berglund, L. A., Strong and Tough Cellulose Nanopaper with High Specific Surface Area and Porosity. Biomacromolecules 2011, 12, (10), 3638-3644.

39. Saito, T.; Uematsu, T.; Kimura, S.; Enomae, T.; Isogai, A., Self-aligned integration of native cellulose nanofibrils towards producing diverse bulk materials. Soft Matter 2011, 7, (19), 8804-8809. 
40. Paakko, M.; Vapaavuori, J.; Silvennoinen, R.; Kosonen, H.; Ankerfors, M.; Lindstrom, T.; Berglund, L. A.; Ikkala, O., Long and entangled native cellulose I nanofibers allow flexible aerogels and hierarchically porous templates for functionalities. Soft Matter 2008, 4, (12), 2492-2499.

41. Josset, S.; Orsolini, P.; Siqueira, G.; Tejado, A.; Tingaut, P.; Zimmermann, T., Energy consumption of the nanofibrillation of bleached pulp, wheat straw and recycled newspaper through a grinding process. Nord. Pulp Pap. Res. J. 2014, 29, (1), 167-175.

42. Olsson, R. T.; Samir, M.; Salazar-Alvarez, G.; Belova, L.; Strom, V.; Berglund, L. A.; Ikkala, O.; Nogues, J.; Gedde, U. W., Making flexible magnetic aerogels and stiff magnetic nanopaper using cellulose nanofibrils as templates. Nat. Nanotechnol. 2010, 5, (8), 584-588.

43. Mihranyan, A.; Llagostera, A. P.; Karmhag, R.; Stromme, M.; Ek, R., Moisture sorption by cellulose powders of varying crystallinity. Int. J. Pharm. 2004, 269, (2), 433-442.

44. Gibson, L. J.; Ashby, M. F., Cellular solids - Structure and properties. Second ed.; CAMBRIDGE UNIVERSITY PRESS: 1997.

45. Segal, L.; Creely, J. J.; Martin, A. E.; Conrad, C. M., An Empirical Method for Estimating the Degree of Crystallinity of Native Cellulose Using the X-Ray Diffractometer. Text. Res. J. 1959, 29, (10), 786-794.

46. Kim, U.-J.; Eom, S. H.; Wada, M., Thermal decomposition of native cellulose: Influence on crystallite size. Polymer Degrad. Stab. 2010, 95, (5), 778-781.

47. French, A. D., Idealized powder diffraction patterns for cellulose polymorphs. Cellulose 2014, $21,(2), 885-896$.

48. Fernandes, A. N.; Thomas, L. H.; Altaner, C. M.; Callow, P.; Forsyth, V. T.; Apperley, D. C.; Kennedy, C. J.; Jarvis, M. C., Nanostructure of cellulose microfibrils in spruce wood. Proc. Natl. Acad. Sci. 2011, 108, (47), E1195-E1203.

49. Kim, U.-J.; Kuga, S.; Wada, M.; Okano, T.; Kondo, T., Periodate Oxidation of Crystalline Cellulose. Biomacromolecules 2000, 1, (3), 488-492.

50. Henriksson, M.; Berglund, L. A.; Isaksson, P.; Lindstrom, T.; Nishino, T., Cellulose nanopaper structures of high toughness. Biomacromolecules 2008, 9, (6), 1579-1585. 
51. Toivonen, M. S.; Kaskela, A.; Rojas, O. J.; Kauppinen, E. I.; Ikkala, O., Ambient-Dried Cellulose Nanofibril Aerogel Membranes with High Tensile Strength and Their Use for Aerosol Collection and Templates for Transparent, Flexible Devices. Adv. Funct. Mater. 2015, 25, (42), 66186626.

52. Ishida, O.; Kim, D. Y.; Kuga, S.; Nishiyama, Y.; Brown, R. M., Microfibrillar carbon from native cellulose. Cellulose 2004, 11, (3-4), 475-480.

53. Kuga, S.; Kim, D. Y.; Nishiyama, Y.; Brown, R. M., Nanofibrillar carbon from native cellulose. Mol. Cryst. Liq. Cryst. 2002, 387.

54. Peng, Y.; Gardner, D. J.; Han, Y.; Kiziltas, A.; Cai, Z.; Tshabalala, M. A., Influence of drying method on the material properties of nanocellulose I: thermostability and crystallinity. Cellulose 2013, 20, (5), 2379-2392.

55. Uetani, K.; Watanabe, Y.; Abe, K.; Yano, H., Influence of drying method and precipitated salts on pyrolysis for nanocelluloses. Cellulose 2014, 21, (3), 1631-1639.

56. Scheirs, J.; Camino, G.; Tumiatti, W., Overview of water evolution during the thermal degradation of cellulose. Europ. Polym. J. 2001, 37, (5), 933-942.

57. Liu, A.; Walther, A.; Ikkala, O.; Belova, L.; Berglund, L. A., Clay Nanopaper with Tough Cellulose Nanofiber Matrix for Fire Retardancy and Gas Barrier Functions. Biomacromolecules 2011, 12, (3), 633-641.

58. Ho, T. T. T.; Zimmermann, T.; Ohr, S.; Caseri, W. R., Composites of Cationic Nanofibrillated Cellulose and Layered Silicates: Water Vapor Barrier and Mechanical Properties. ACS Appl. Mater. Inter. 2012, 4, (9), 4832-4840.

59. Wang, Z.; McDonald, A. G.; Westerhof, R. J. M.; Kersten, S. R. A.; Cuba-Torres, C. M.; Ha, S.; Pecha, B.; Garcia-Perez, M., Effect of cellulose crystallinity on the formation of a liquid intermediate and on product distribution during pyrolysis. J. Anal. Appl. Pyrolysis 2013, 100, 56-66.

60. Ozawa, T., A new method of analyzing thermogravimetric data. Bull. Chem. Soc. Jpn. 1965, $38,(11), 1881-1886$.

61. Starink, M. J., The determination of activation energy from linear heating rate experiments: a comparison of the accuracy of isoconversion methods. Thermochim. Acta 2003, 404, (1-2), 163-176. 
62. Milosavljevic, I.; Suuberg, E. M., Cellulose thermal-decomposition kinetics-global mass-loss kinetics. Ind. Eng. Chem. Res. 1995, 34, (4), 1081-1091.

63. Back, E. L.; Htun, M. T.; Jackson, M.; Johanson, F., Ultrasonic measurements of thermal softening of paper products and influence of thermal auto-cross-linking reactions. Tappi 1967, 50, (11P1), 542-547.

64. Kilzer, F. J.; Broido, A., Speculations on nature of cellulose pyrolysis. Pyrodynamics 1965, 2, $(2-3), 151-163$.

65. Pastorova, I.; Botto, R. E.; Arisz, P. W.; Boon, J. J., Cellulose char structure - a combined analytical py-gc-ms, ftir, and nmr-study. Carbohyd. Res. 1994, 262, (1), 27-47.

66. Boon, J. J.; Pastorova, I.; Botto, R. E.; Arisz, P. W., Structural studies on cellulose pyrolysis and cellulose chars by pyms, pygcms, ftir, nmr and by wet chemical techniques. Biomass Bioenergy 1994, 7, (1-6), 25-32.

67. Lin, Y.-C.; Cho, J.; Tompsett, G. A.; Westmoreland, P. R.; Huber, G. W., Kinetics and Mechanism of Cellulose Pyrolysis. J. Phys. Chem. C 2009, 113, (46), 20097-20107.

68. Chaiwat, W.; Hasegawa, I.; Kori, J.; Mae, K., Examination of Degree of Cross-Linking for Cellulose Precursors Pretreated with Acid/Hot Water at Low Temperature. Ind. Eng. Chem. Res. 2008, 47, (16), 5948-5956.

69. Radlein, D.; Piskorz, J.; Scott, D. S., Fast pyrolysis of natural polysaccharides as a potential industrial-process. J. Anal. Appl. Pyrolysis 1991, 19, 41-63.

70. Broido, A.; Nelson, M. A., Char yield on pyrolysis of cellulose. Combust. Flame 1975, 24, 263-268.

71. Wang, Z.; Pecha, B.; Westerhof, R. J. M.; Kersten, S. R. A.; Li, C.-Z.; McDonald, A. G.; Garcia-Perez, M., Effect of Cellulose Crystallinity on Solid/Liquid Phase Reactions Responsible for the Formation of Carbonaceous Residues during Pyrolysis. Ind. Eng. Chem. Res. 2014, 53, (8), $2940-$ 2955.

72. Kumar, M.; Gupta, R. C., Scanning electron-microscopic study of acacia and eucalyptus wood chars. J. Mater. Sci. 1995, 30, (2), 544-551. 
73. Tang, M. M.; Bacon, R., Carbonization of cellulose fibers .1. low temperature pyrolysis. Carbon 1964, 2, (3), 211-220.

74. Zhang, X.; Yang, W.; Blasiak, W., Thermal decomposition mechanism of levoglucosan during cellulose pyrolysis. J. Anal. Appl. Pyrolysis 2012, 96, 110-119.

75. Shen, D. K.; Gu, S., The mechanism for thermal decomposition of cellulose and its main products. Bioresour. Technol. 2009, 100, (24), 6496-6504.

76. Chen, G.; Yu, Q.; Sjöström, K., Reactivity of char from pyrolysis of birch wood. J. Anal. Appl. Pyrolysis 1997, 40, 491-499.

77. Antal, M. J.; Grønli, M., The Art, Science, and Technology of Charcoal Production. Ind. Eng. Chem. Res. 2003, 42, (8), 1619-1640.

78. Weinstetn, M.; Broido, A., Pyrolysis-Crystallinity Relationships in Cellulose. Combust. Sci. Technol. 1970, 1, (4), 287-292.

79. Broido, A.; Javier-Son, A. C.; Ouano, A. C.; Barrall, E. M., Molecular weight decrease in the early pyrolysis of crystalline and amorphous cellulose. J. Appl. Polym. Sci. 1973, 17, (12), 3627-3635. 80. Lédé, J., Cellulose pyrolysis kinetics: An historical review on the existence and role of intermediate active cellulose. J. Anal. Appl. Pyrolysis 2012, 94, 17-32.

81. Hosoya, T.; Sakaki, S., Levoglucosan Formation from Crystalline Cellulose: Importance of a Hydrogen Bonding Network in the Reaction. Chemsuschem 2013, 6, (12), 2356-2368.

82. Chorley, C., The destructive distillation of wood. J. Soc. Chem. Ind. 1892, 11, (11), 872-874.

83. Mok, W. S. L.; Antal, M. J., Effects of pressure on biomass pyrolysis. I. Cellulose pyrolysis products. Thermochim. Acta 1983, 68, (2), 155-164.

84. Klason, P., Versuch einer Theorie der Trockendestillation von Holz. I. Journal für Praktische Chemie 1914, 90, (1), 413-447.

85. Yu, Y.; Wu, H., Significant Differences in the Hydrolysis Behavior of Amorphous and Crystalline Portions within Microcrystalline Cellulose in Hot-Compressed Water. Ind. Eng. Chem. Res. 2010, 49, (8), 3902-3909. 
86. Bi, H.; Yin, Z.; Cao, X.; Xie, X.; Tan, C.; Huang, X.; Chen, B.; Chen, F.; Yang, Q.; Bu, X.; Lu, X.; Sun, L.; Zhang, H., Carbon Fiber Aerogel Made from Raw Cotton: A Novel, Efficient and Recyclable Sorbent for Oils and Organic Solvents. Adv. Mater. 2013, 25, (41), 5916-5921.

87. Han, S.; Sun, Q.; Zheng, H.; Li, J.; Jin, C., Green and facile fabrication of carbon aerogels from cellulose-based waste newspaper for solving organic pollution. Carbohydr. Polym. 2016, 136, 95-100.

88. Jiang, F.; Hsieh, Y.-L., Amphiphilic superabsorbent cellulose nanofibril aerogels. J. Mater. Chem. A 2014, 2, (18), 6337-6342.

89. Šimon, P.; Dubaj, T.; Cibulková, Z., Equivalence of the Arrhenius and non-Arrhenian temperature functions in the temperature range of measurement. J. Therm. Anal. Calorim. 2015, 120, (1), 231-238.

90. Vyazovkin, S.; Burnham, A. K.; Criado, J. M.; Pérez-Maqueda, L. A.; Popescu, C.; Sbirrazzuoli, N., ICTAC Kinetics Committee recommendations for performing kinetic computations on thermal analysis data. Thermochim. Acta 2011, 520, (1-2), 1-19.

91. Poletto, M.; Zattera, A. J.; Forte, M. M. C.; Santana, R. M. C., Thermal decomposition of wood: Influence of wood components and cellulose crystallite size. Bioresour. Technol. 2012, 109, 148-153.

92. Ornaghi, H. L.; Poletto, M.; Zattera, A. J.; Amico, S. C., Correlation of the thermal stability and the decomposition kinetics of six different vegetal fibers. Cellulose 2014, 21, (1), 177-188. 
Drying and pyrolysis of cellulose nanofibers from wood, bacteria and algae for char application in oil absorption and dyes adsorption

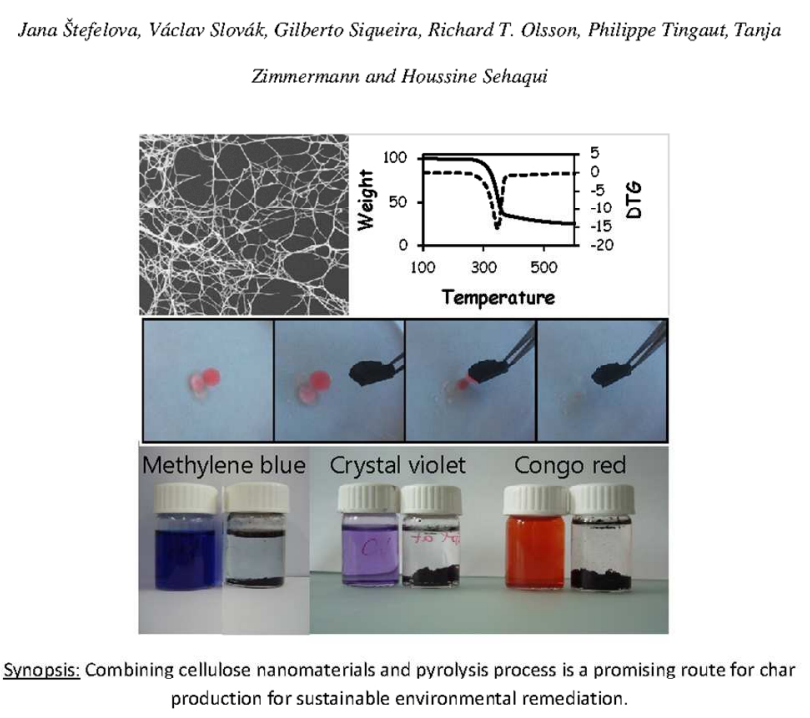
production for sustainable environmental remediation. 

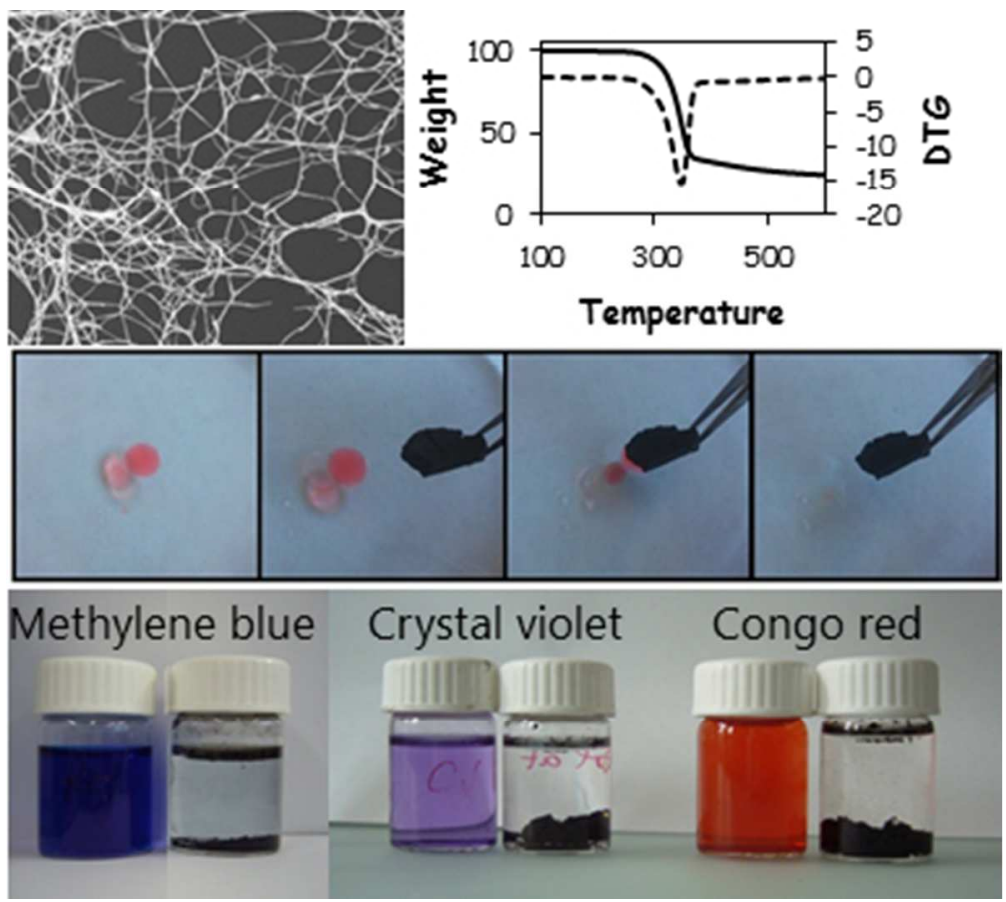

$101 \times 90 \mathrm{~mm}(96 \times 96 \mathrm{DPI})$ 